Supporting Information for:

\title{
Synthesis and Characterization of Water-Soluble Silver and Palladium Imidazol-2-ylidene Complexes with Non-Coordinated Anionic Substituents
}

Lucas R. Moore, ${ }^{\dagger}$ Sheritta M. Cooks, ${ }^{\dagger}$ Matthew S. Anderson, ${ }^{\dagger}$ Hans-Jörg Schanz, ${ }^{* *}$ Scott T. Griffin, ${ }^{\dagger}$ Robin D. Rogers, ${ }^{\dagger}$ Marion C. Kirk, ${ }^{\S}$ and Kevin H. Shaughnessy ${ }^{\dagger *}$

Department of Chemistry and Center for Green Manufacturing, The University of Alabama, Tuscaloosa, AL 35487-0336, Department of Chemistry and Biochemistry, The University of Southern Mississippi, 118 College Dr., Hattiesburg, MS 39406-5043, and Comprehensive Cancer Center Mass Spectrometry Shared Facility, University of Alabama at Birmingham, Birmingham, AL 35294.

\section{Table of Contents}

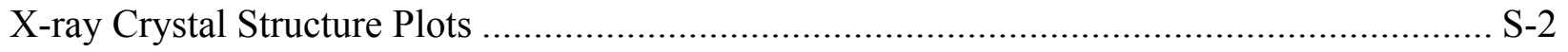

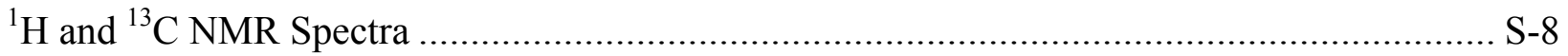

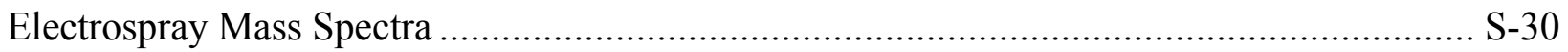

The University of Alabama

* The University of Southern Mississippi

${ }^{\S}$ University of Alabama at Birmingham 


\section{X-ray Crystal Structure Plots}

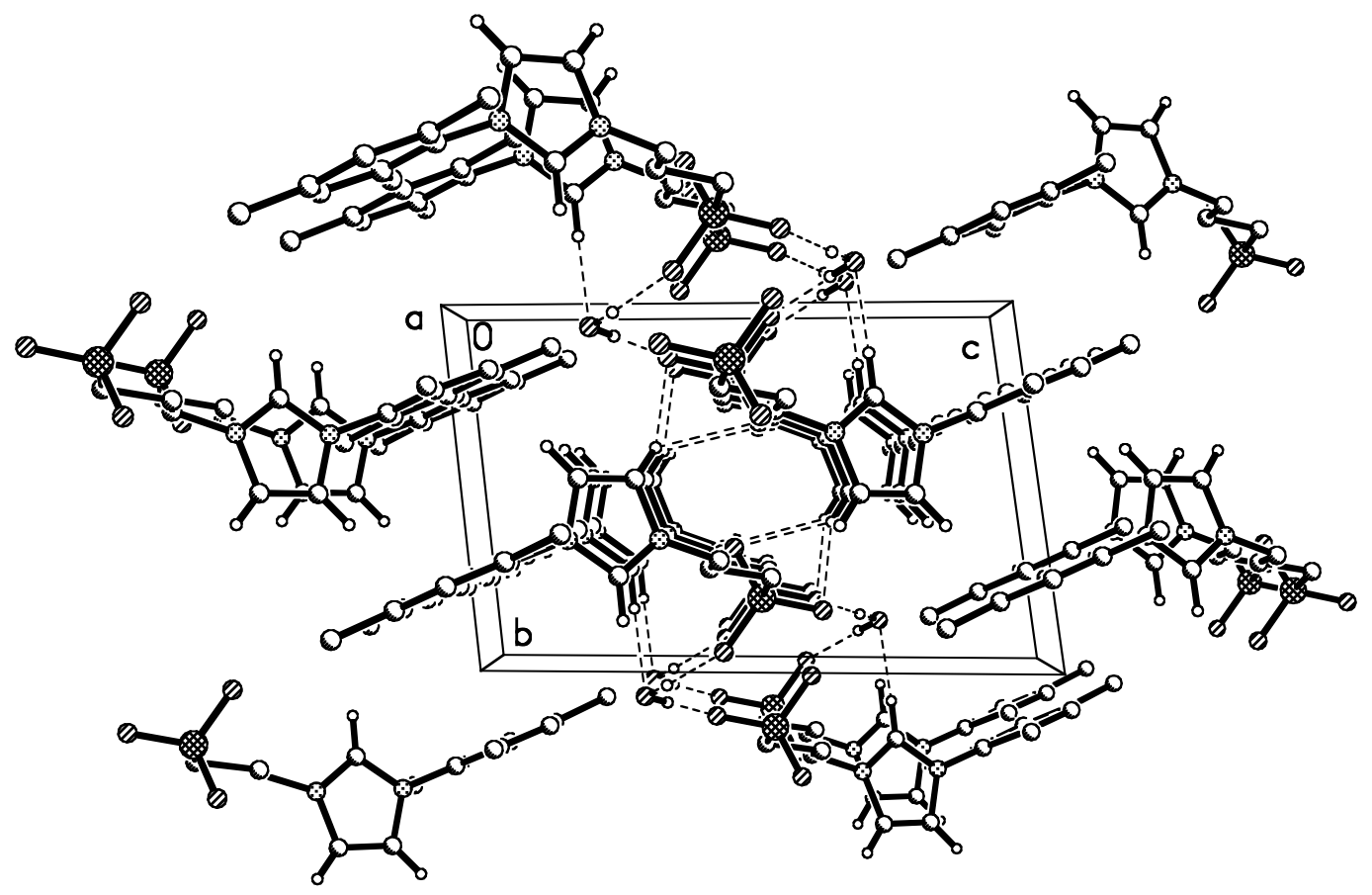

Figure S1. Crystal packing diagram for 1-mesityl-3-(3-sulfonatopropyl)imidazolium monohydrate $\left(\mathbf{2} \cdot \mathrm{H}_{2} \mathrm{O}\right)$. 


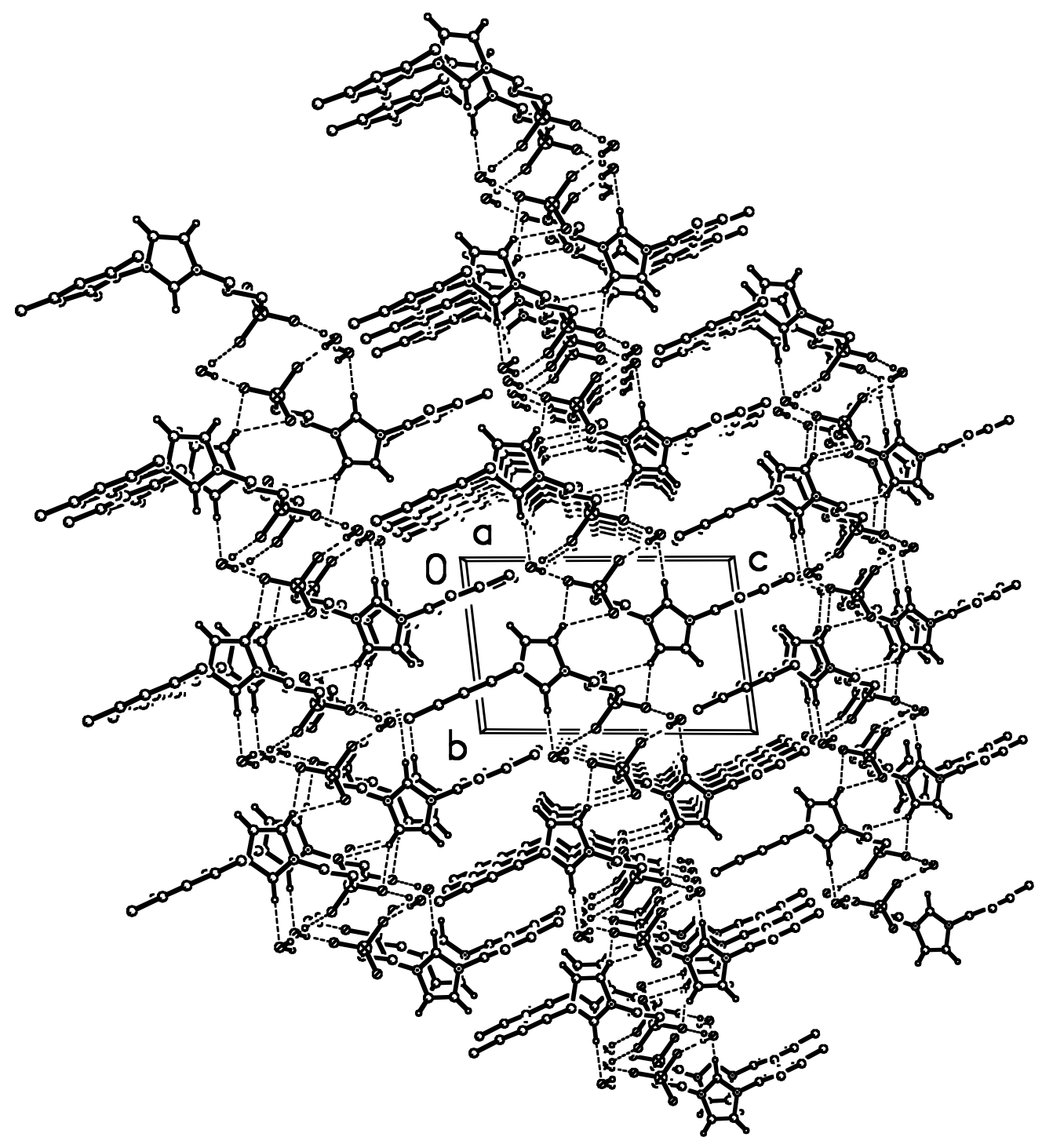

Figure S2. Expanded crystal packing diagram for $\mathbf{2} \cdot \mathrm{H}_{2} \mathrm{O}$. 


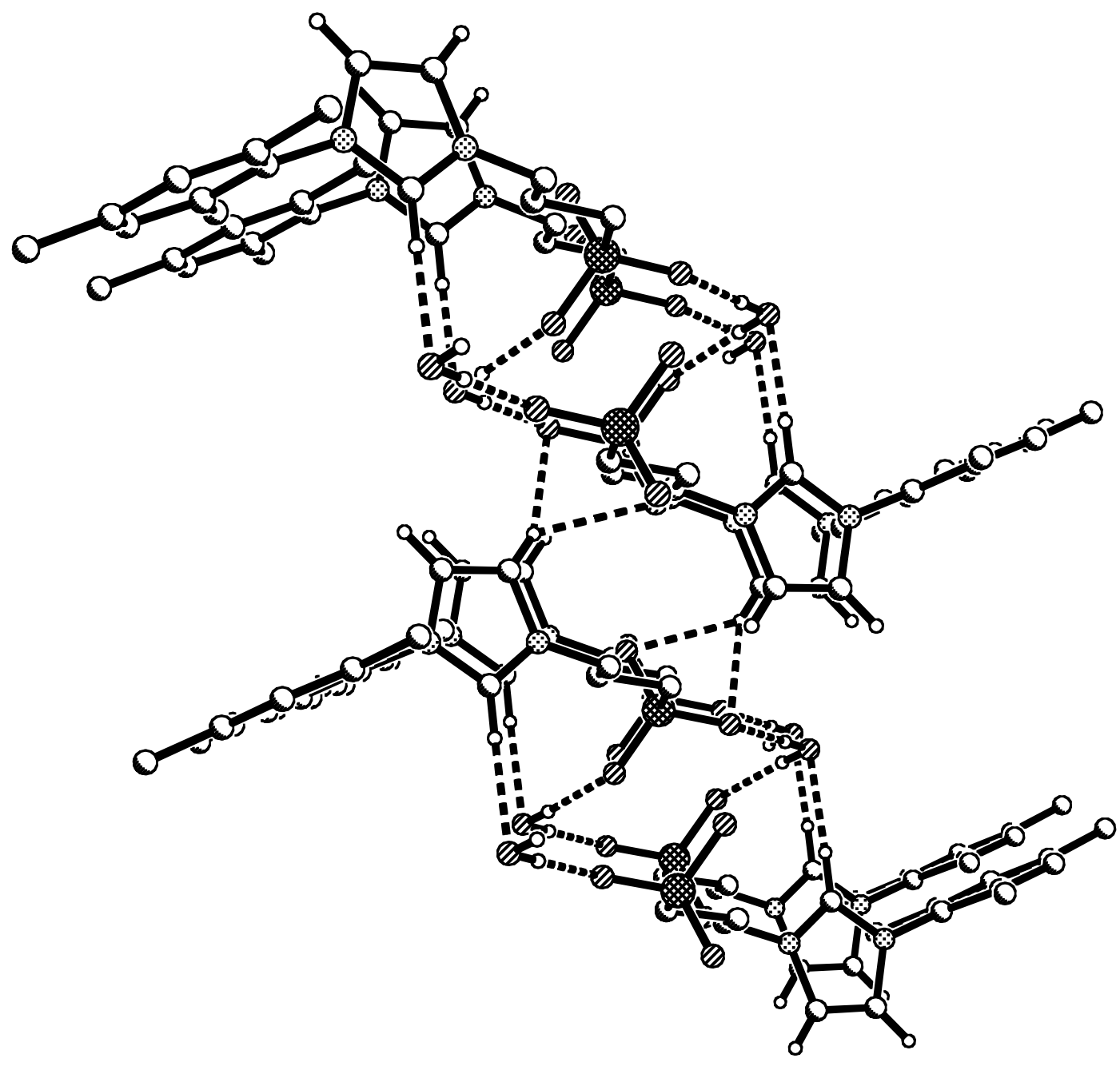

Figure S3. Hydrogen bonding interactions in the crystal structure of $2 \cdot \mathrm{H}_{2} \mathrm{O}$, down the $a$ axis. 


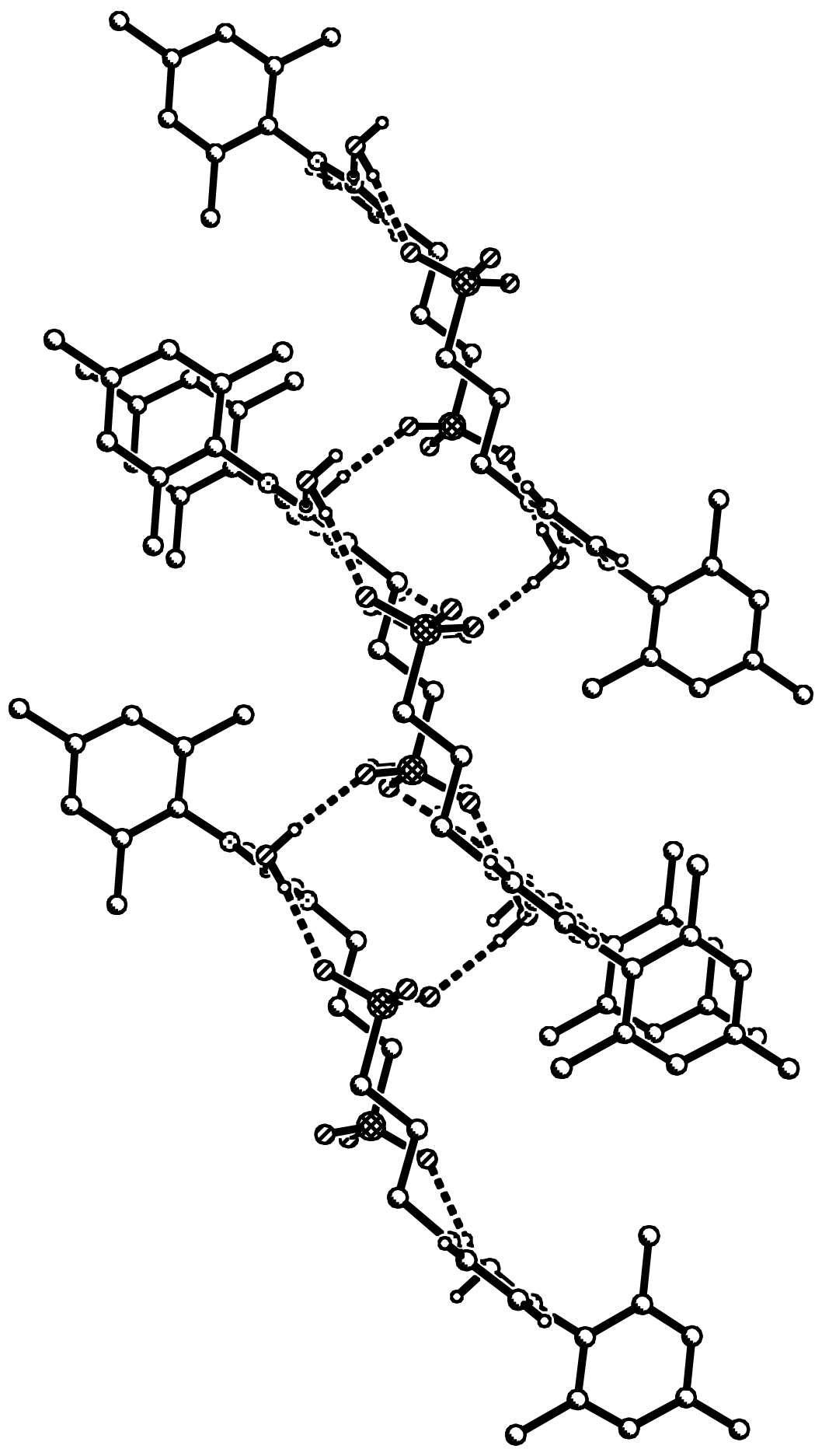

Figure S4. Hydrogen bonding interactions in the crystal structure of $2 \cdot \mathrm{H}_{2} \mathrm{O}$, down the $b$ axis. 


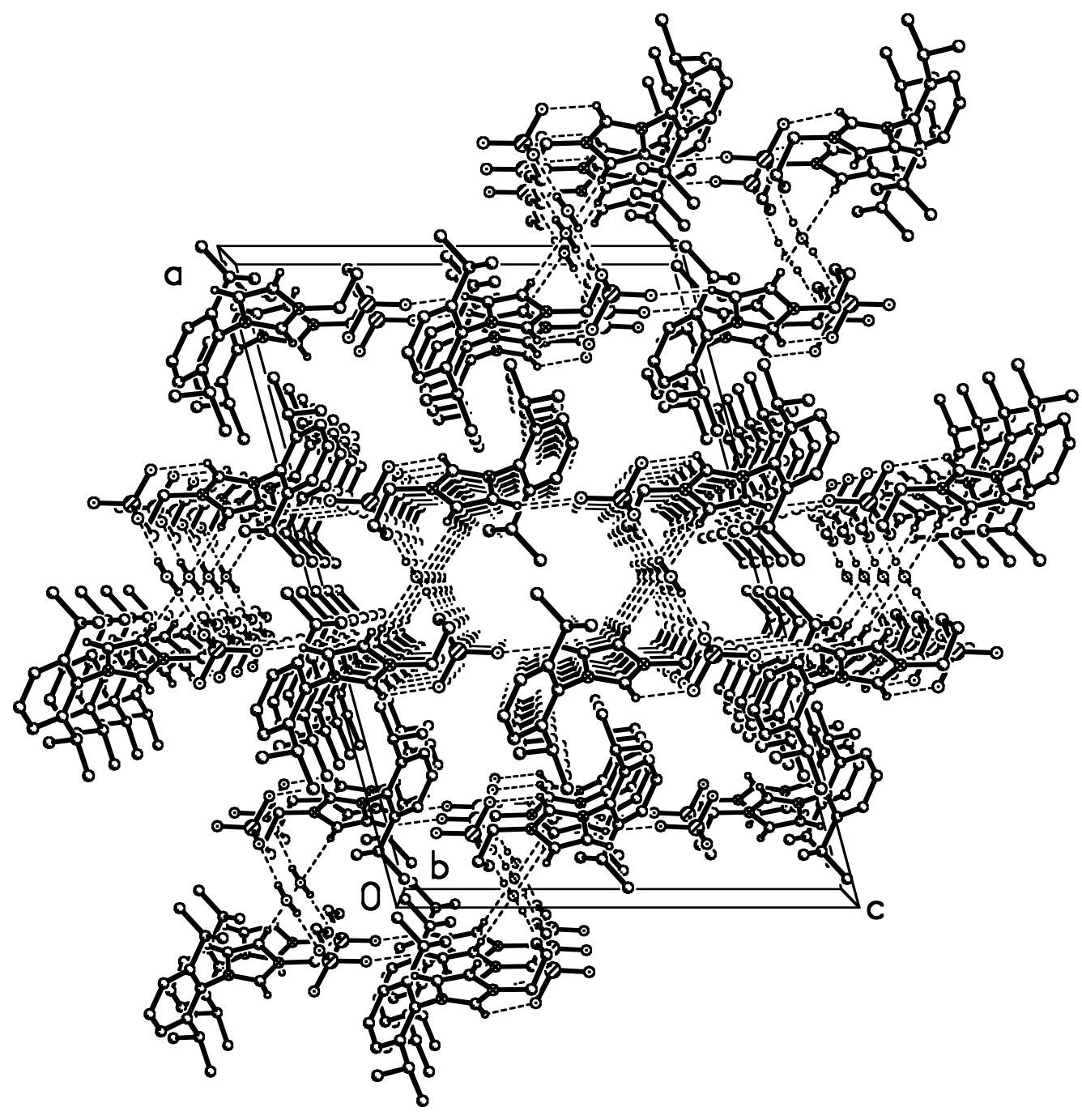

Figure S5. Crystal packing diagram of $3 \cdot 0.5 \mathrm{H}_{2} \mathrm{O}$. 


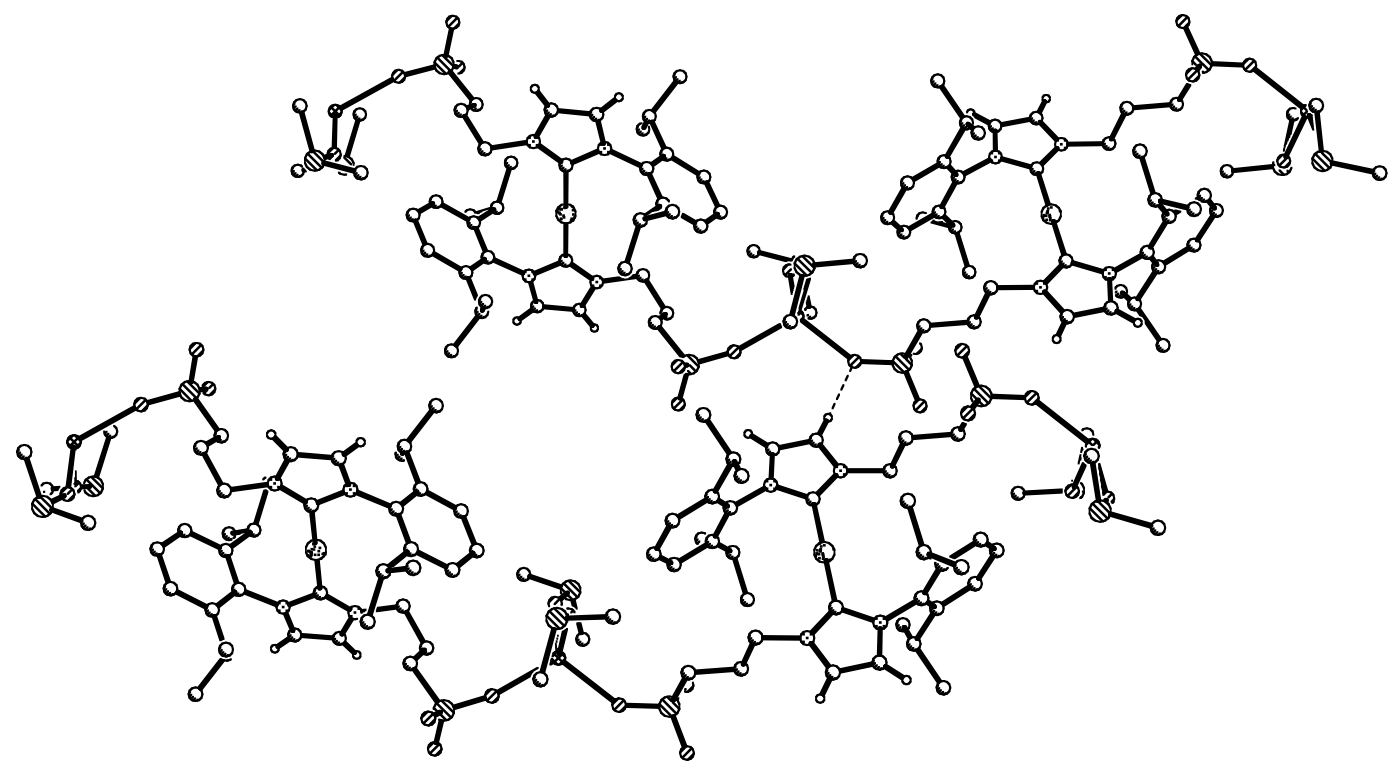

Figure S6. Polymeric structure of $\left[(3)_{2} \mathrm{Ag}\right] \mathrm{Na}^{+} \cdot 4 \mathrm{DMSO}$ showing the interstrand hydrogen bond between the $\mathrm{C} 5$ proton and a sulfonate oxygen.

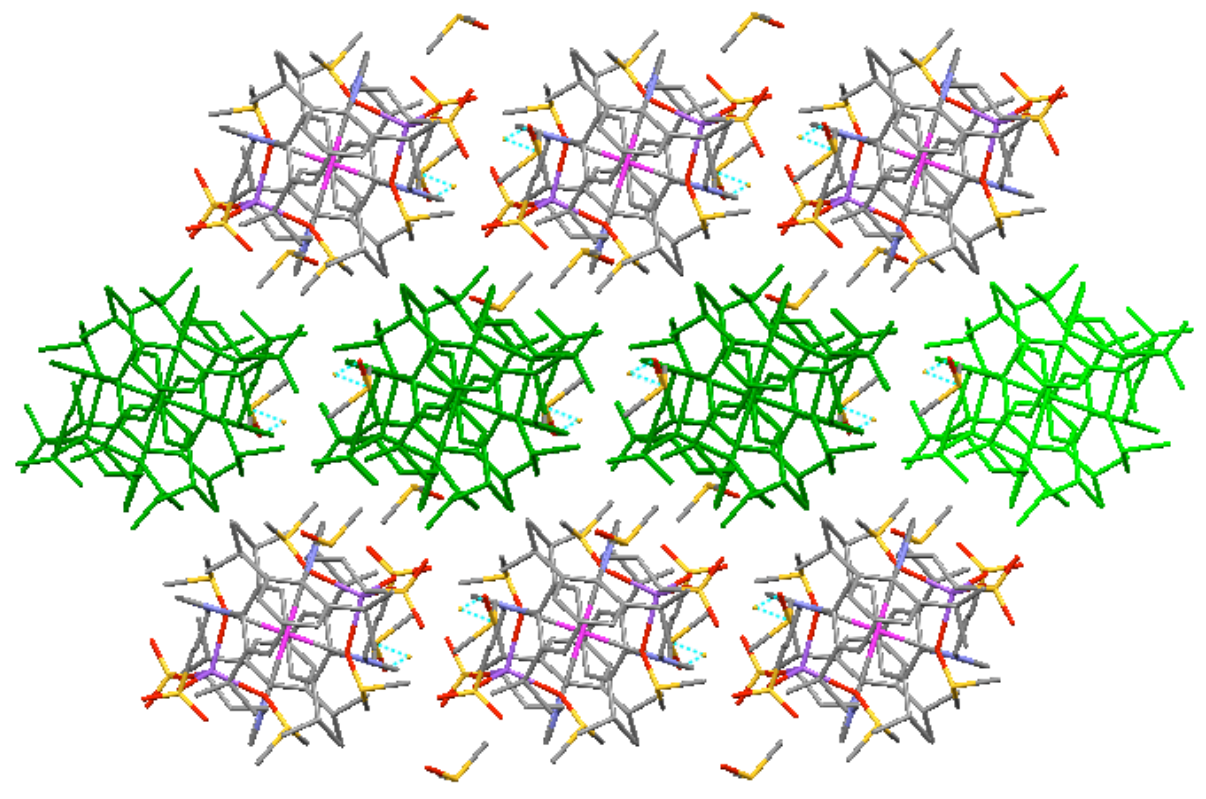

Figure S7. Crystal packing diagraom of 8.4DMSO looking down the polymeric axis. 


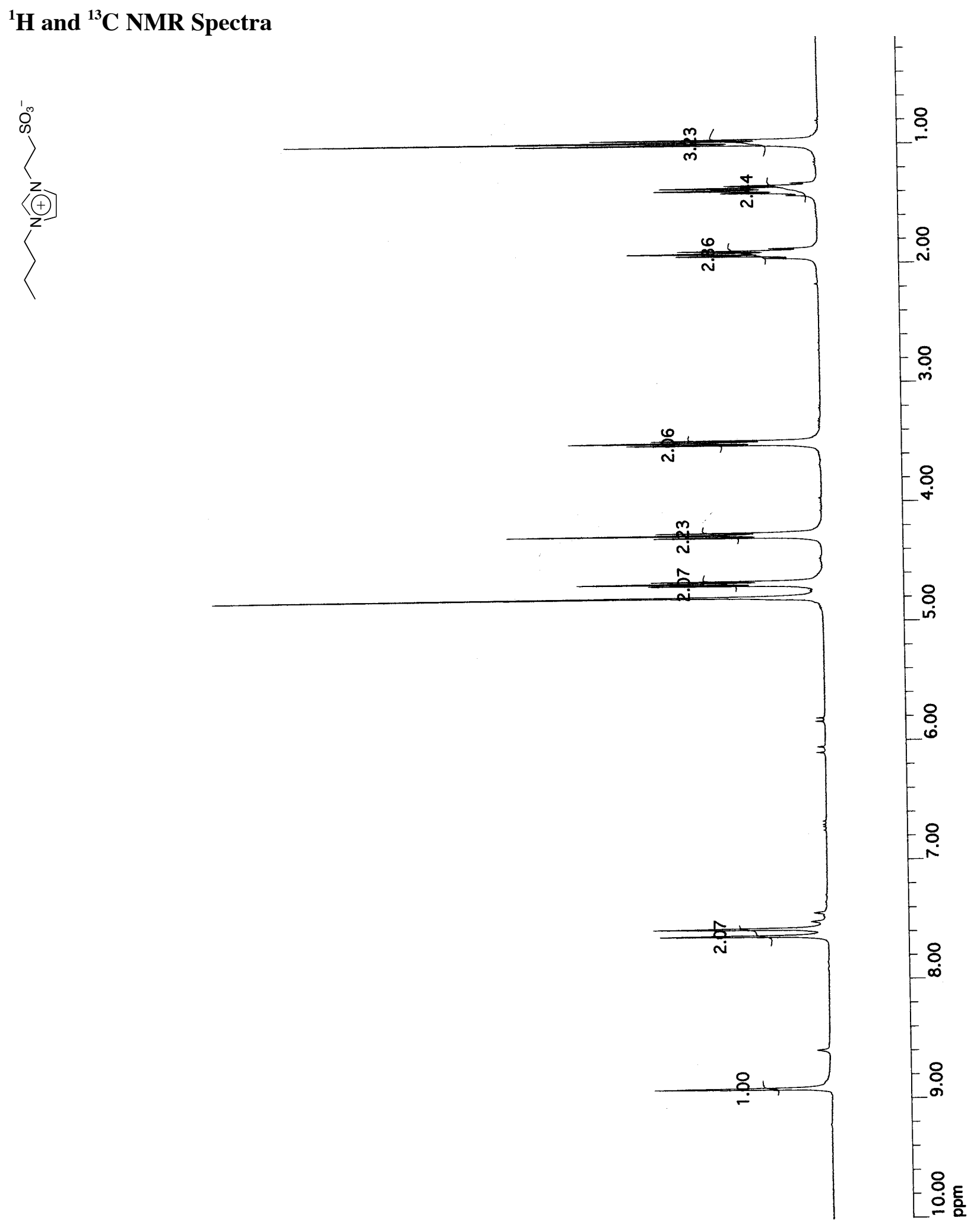

Figure S8. ${ }^{1} \mathrm{H}$ NMR spectrum of $\mathbf{1}$ in $\mathrm{D}_{2} \mathrm{O}$. 

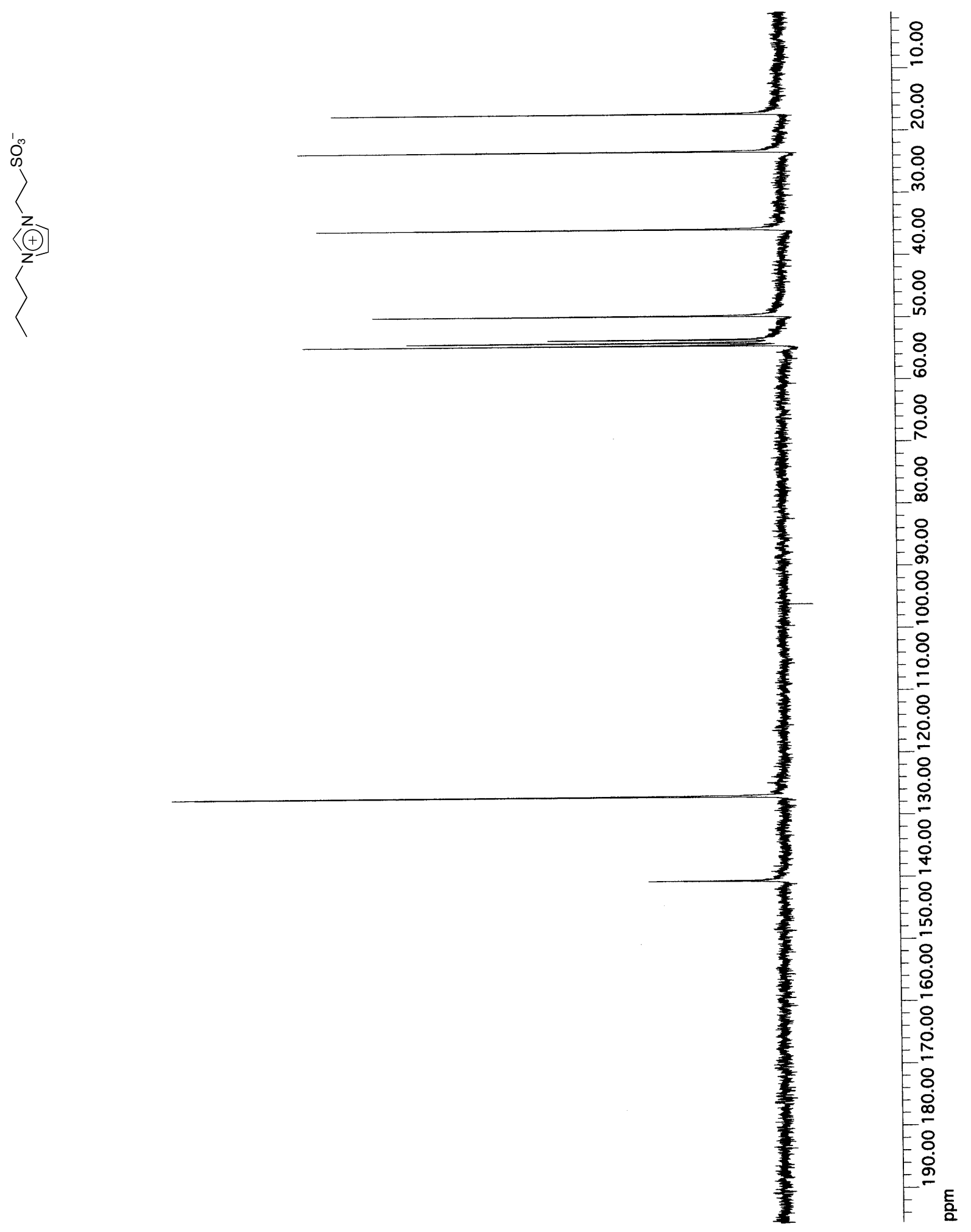

Figure S9. ${ }^{13} \mathrm{C}$ NMR spectrum of $\mathbf{1}$ in $\mathrm{D}_{2} \mathrm{O}$ with $\mathrm{CH}_{3} \mathrm{OH}$ as an internal standard. 

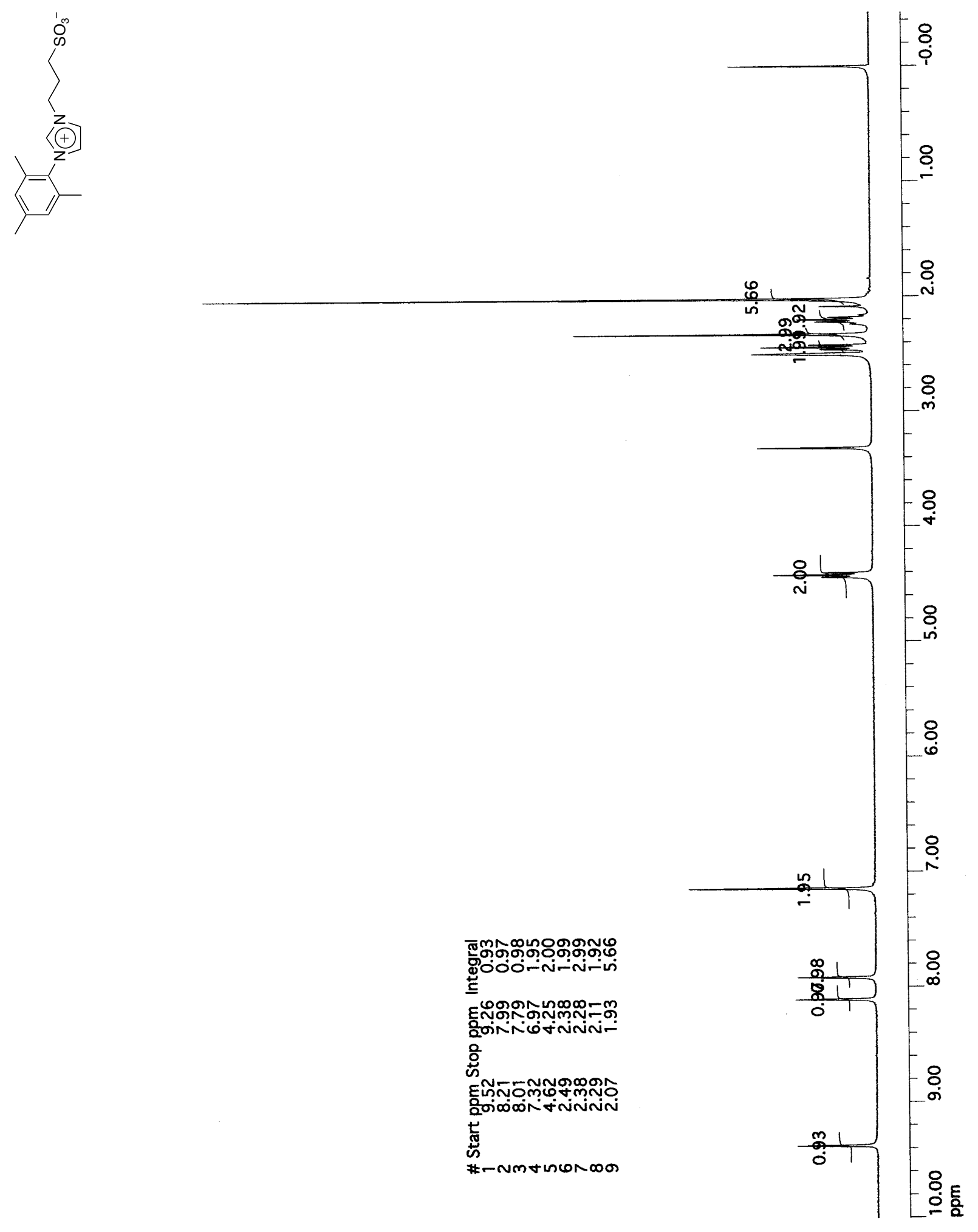

Figure S10. ${ }^{1} \mathrm{H}$ NMR spectrum of $\mathbf{2}$ in DMSO- $d_{6}$ 

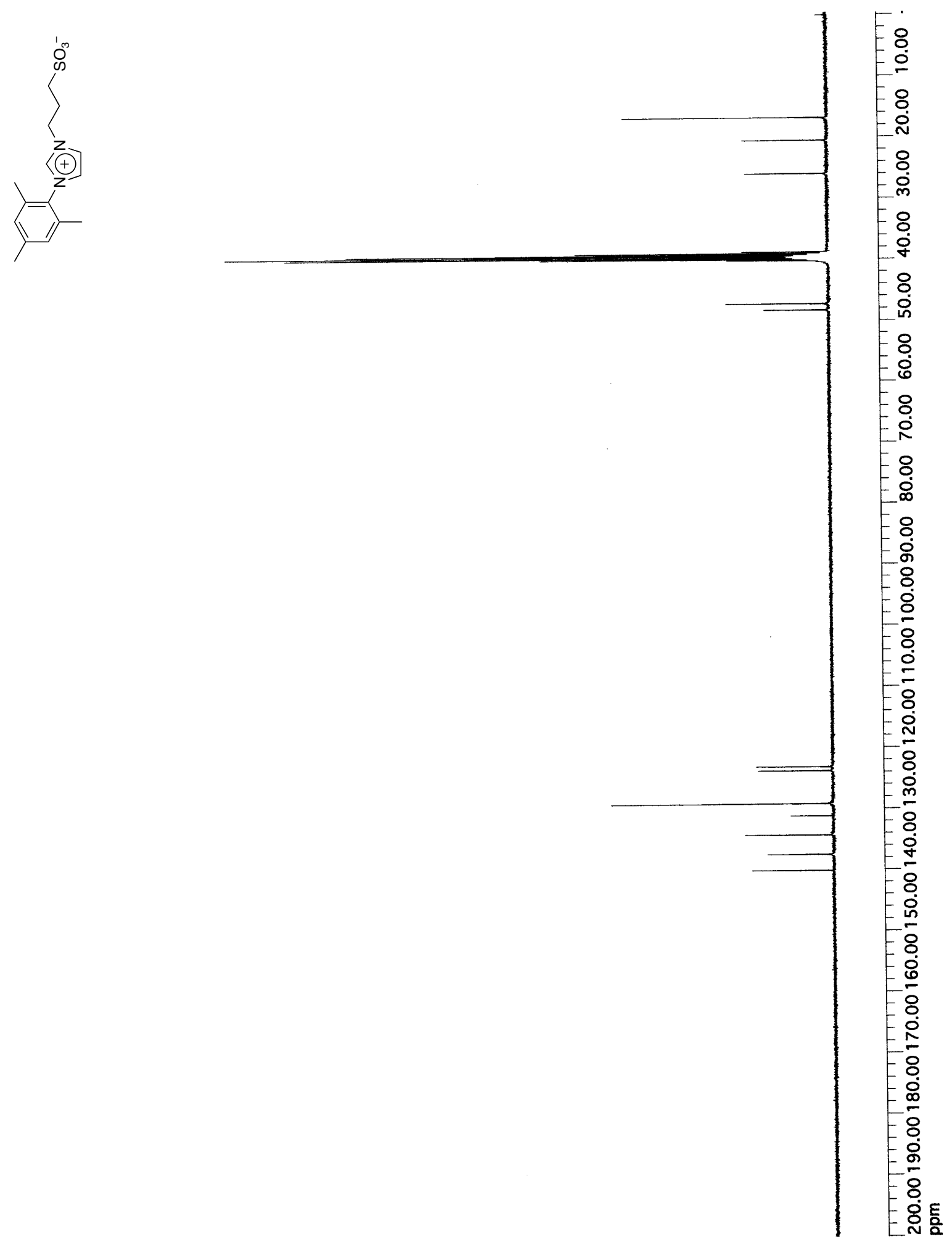

Figure S11. ${ }^{13} \mathrm{C}$ NMR spectrum of 2 in DMSO- $d_{6}$ 

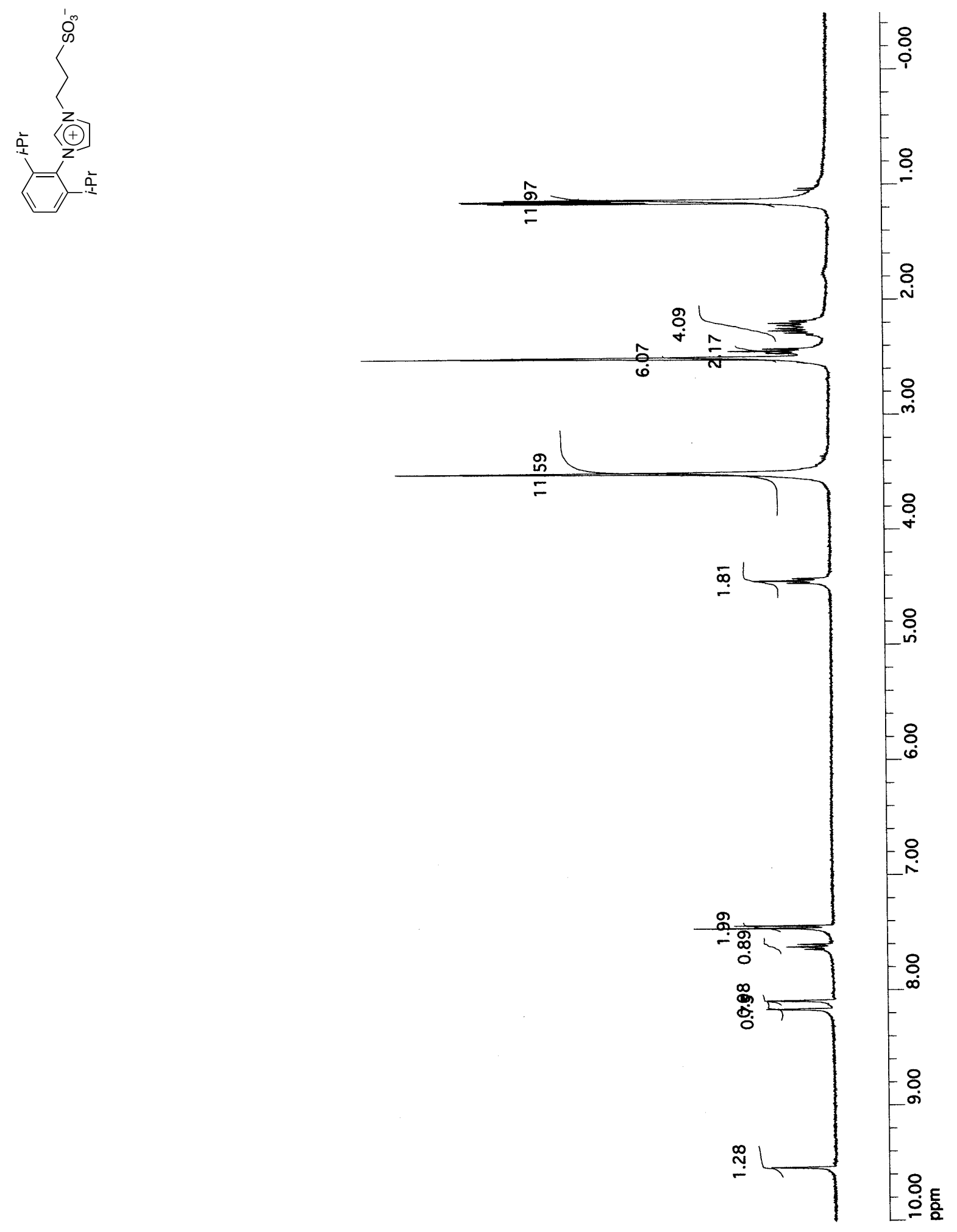

Figure S12. ${ }^{1} \mathrm{H}$ NMR spectrum of 3 in DMSO- $d_{6}$ 


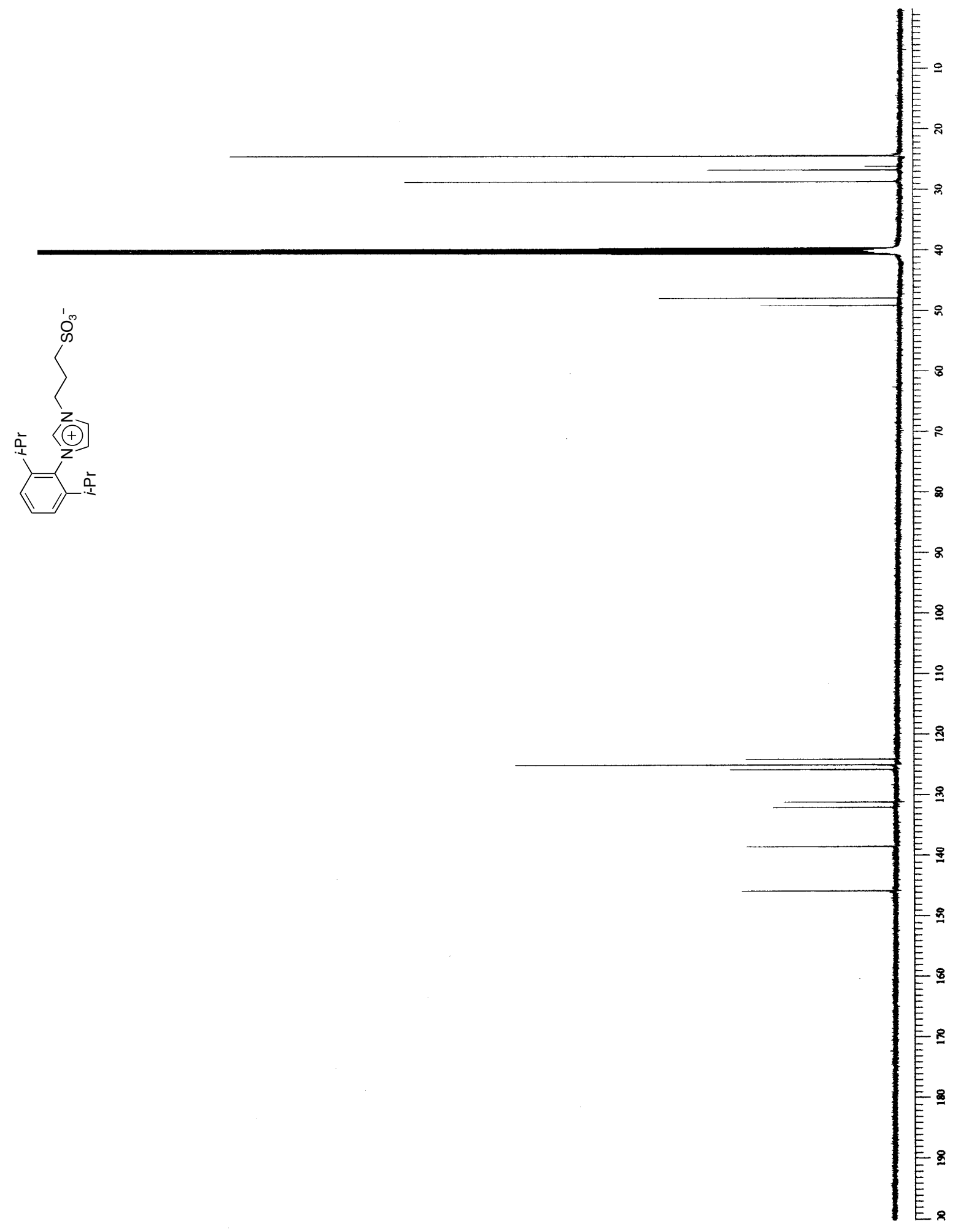

Figure S13. ${ }^{13} \mathrm{C}$ NMR spectrum of 3 in DMSO- $d_{6}$ 


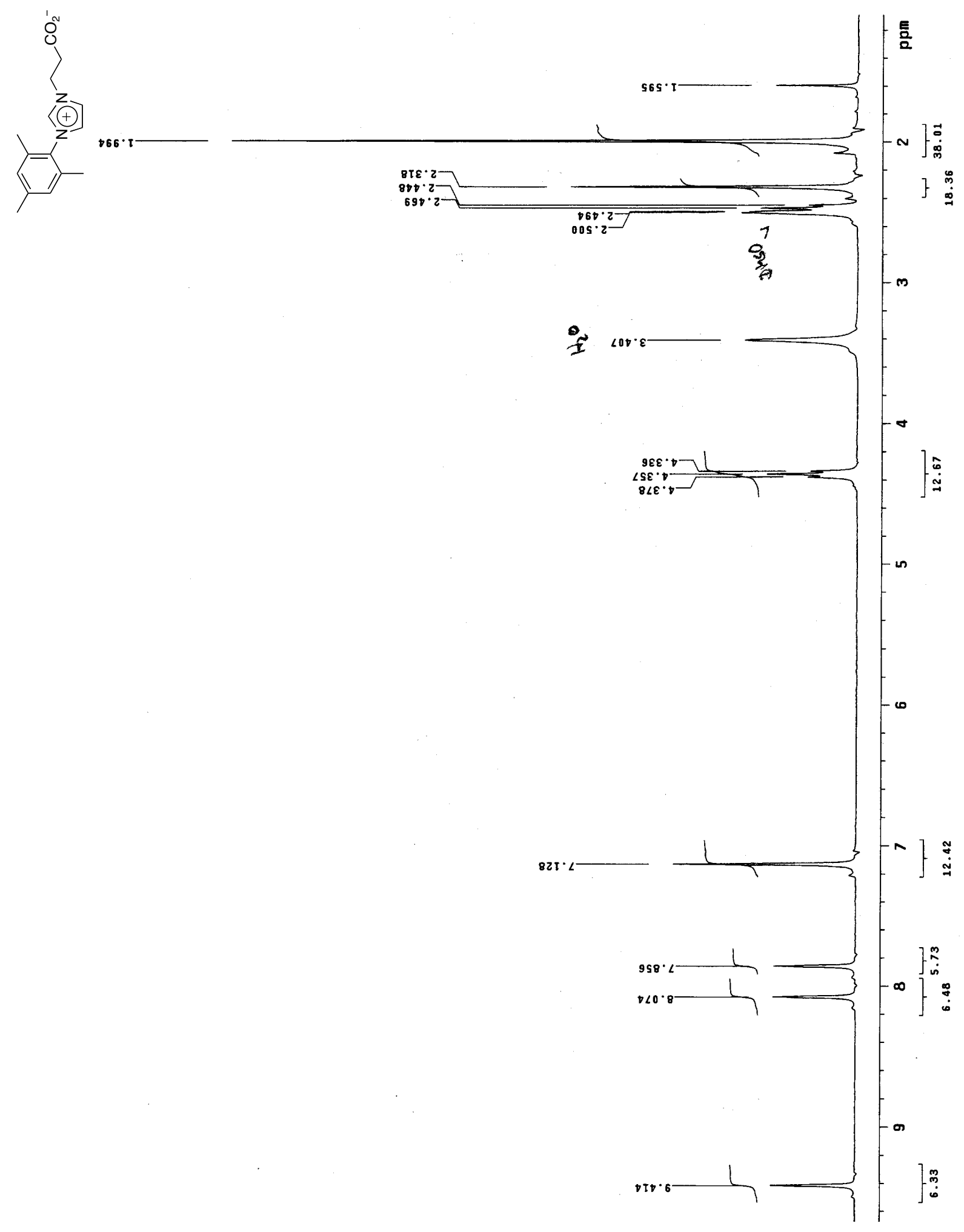

Figure S14. ${ }^{1} \mathrm{H}$ NMR spectrum of 4 in DMSO- $d_{6}$. 


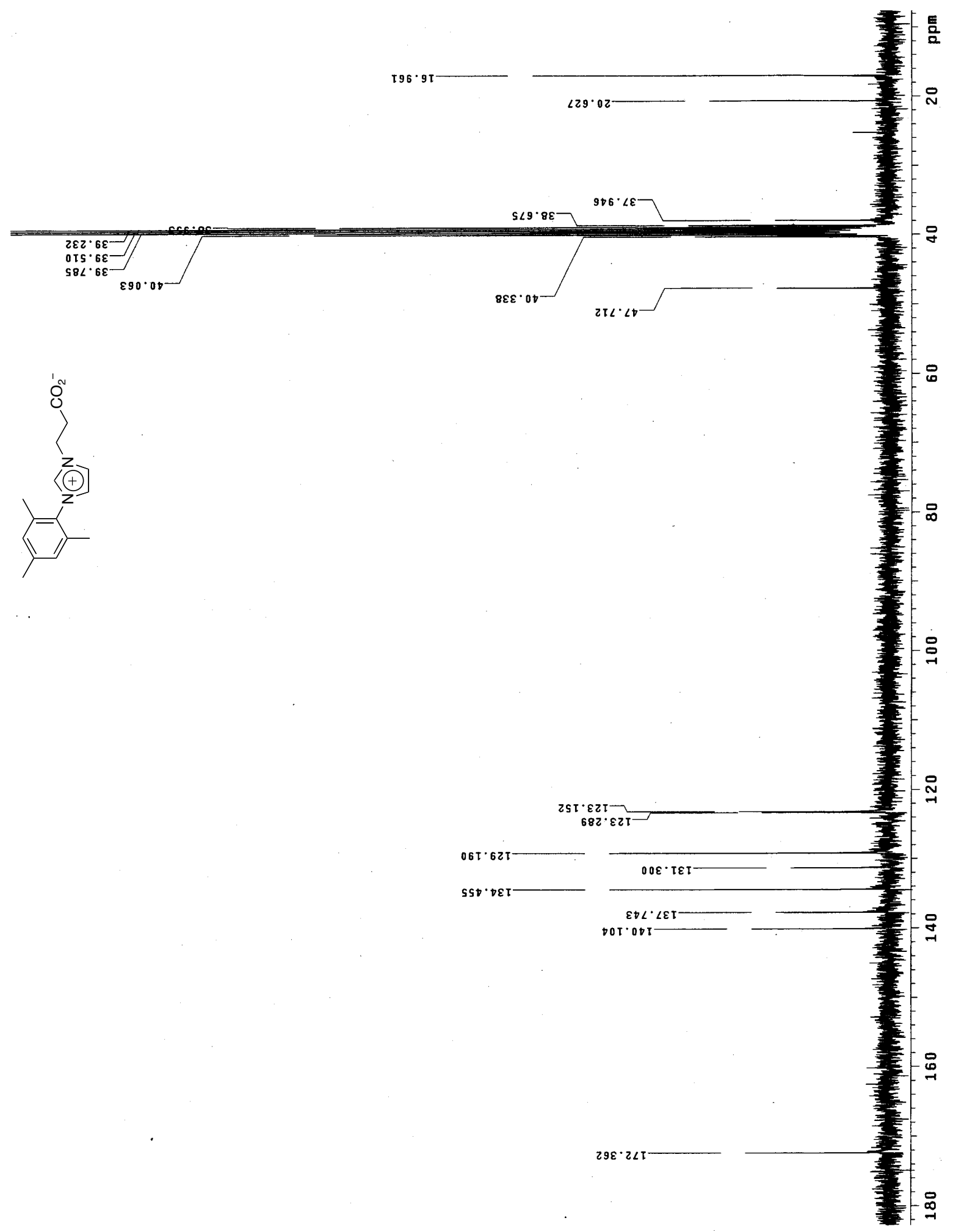

Figure S15. ${ }^{13} \mathrm{C}$ NMR spectrum of 4 in DMSO- $d_{6}$. 


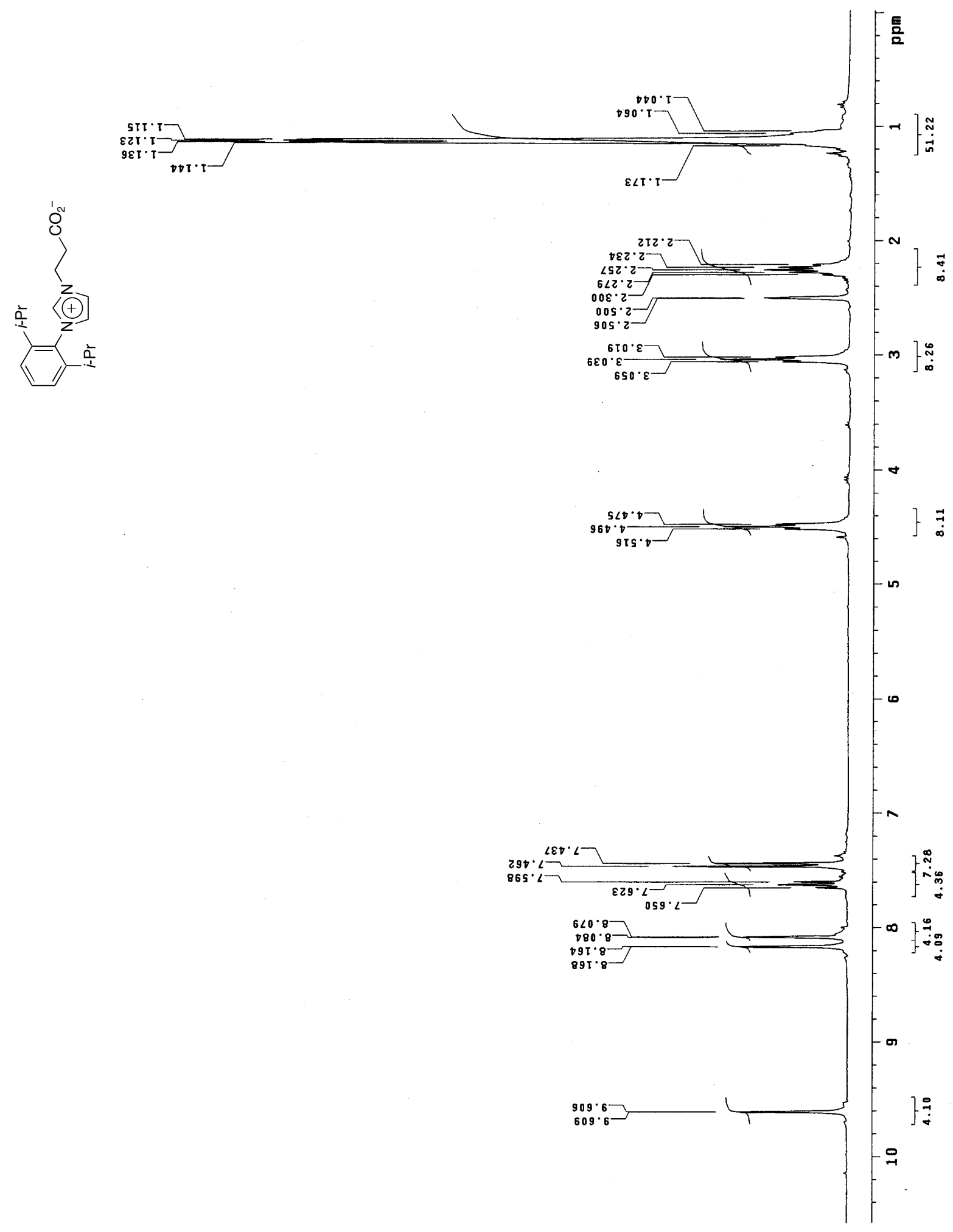

Figure S16. ${ }^{1} \mathrm{H}$ NMR spectrum of 5 in DMSO- $d_{6}$. 


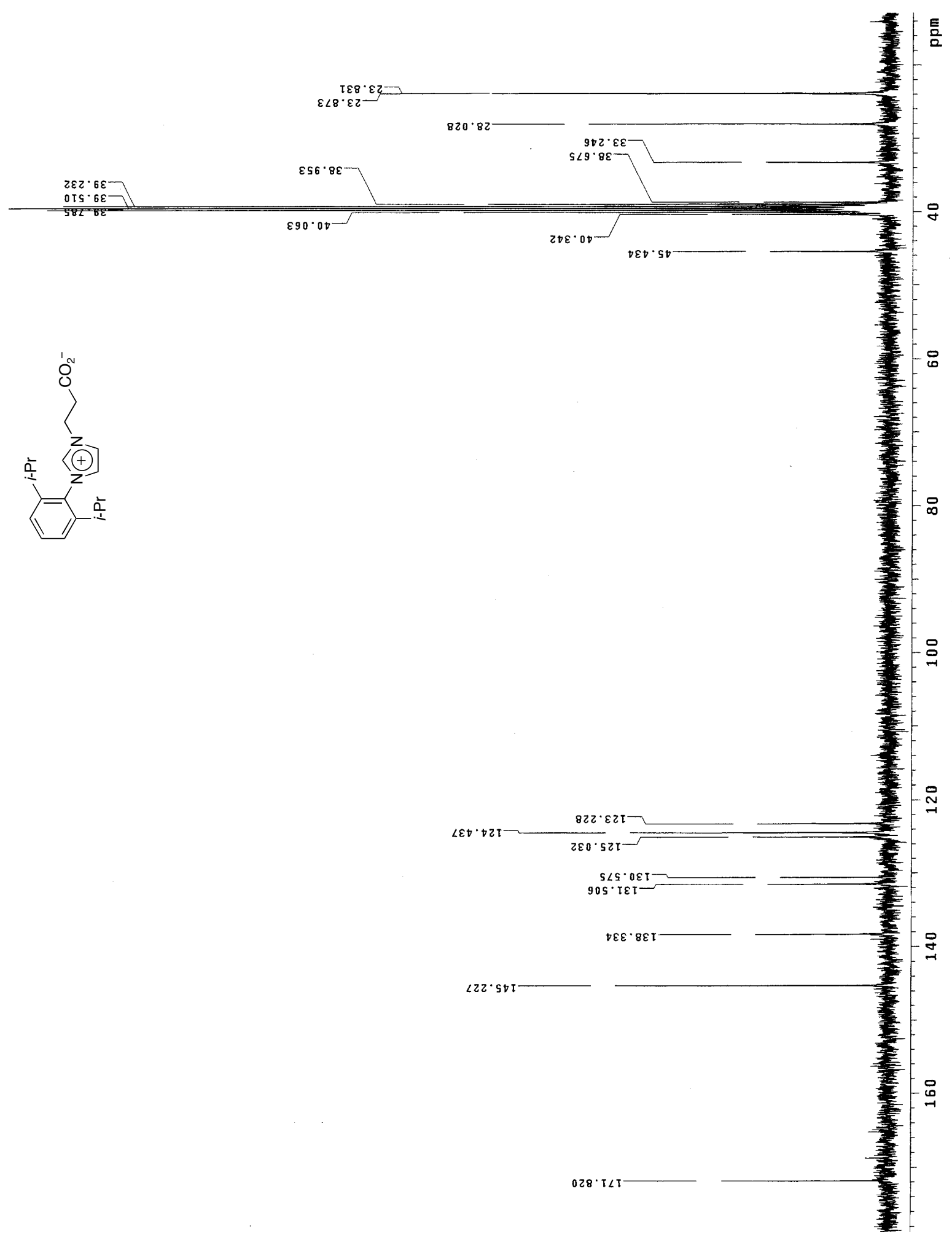

Figure S17. ${ }^{13} \mathrm{C}$ NMR spectrum of 5 in DMSO- $d_{6}$. 

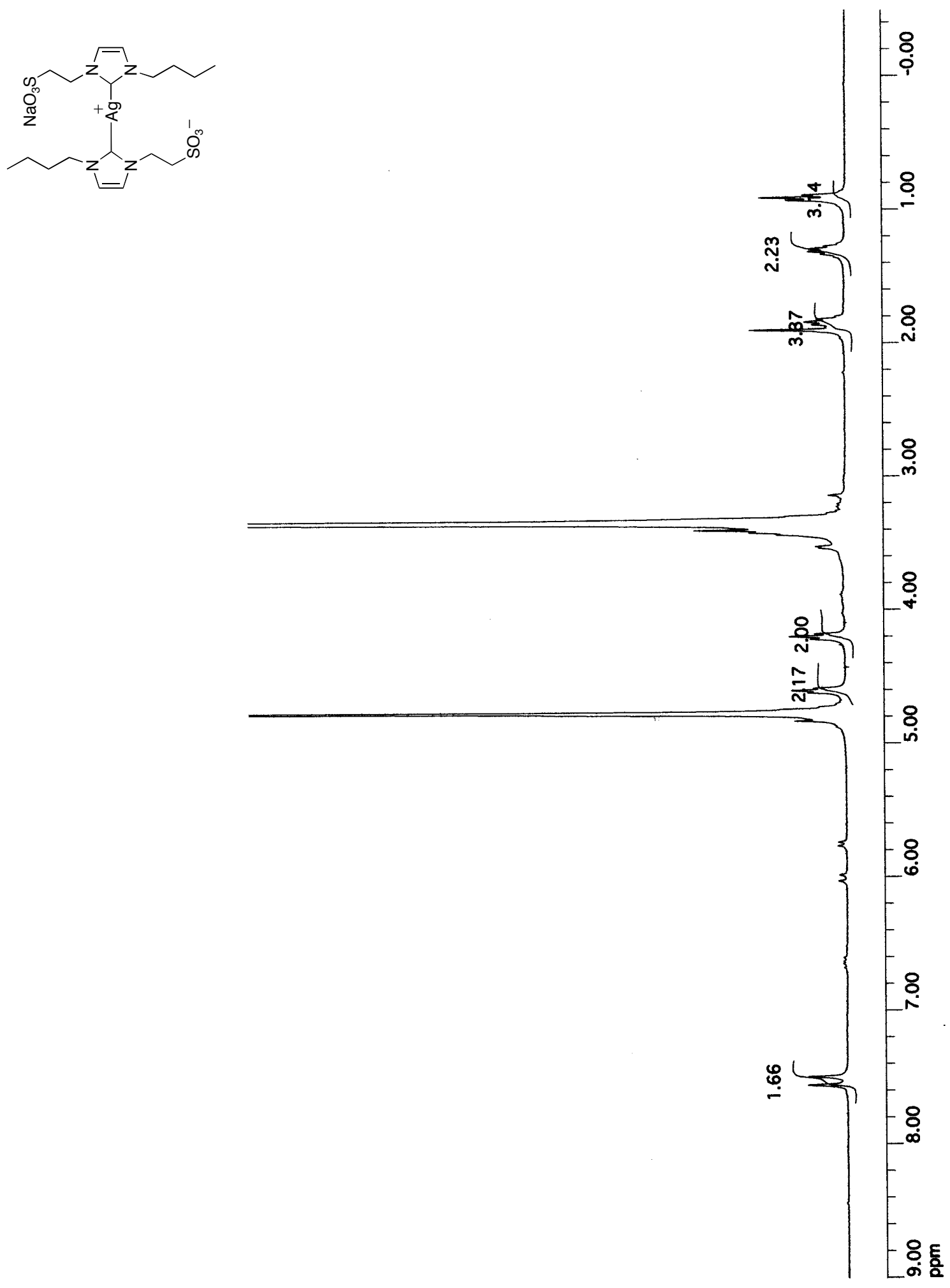

Figure S18. ${ }^{1} \mathrm{H}$ NMR spectrum of 6 in $\mathrm{D}_{2} \mathrm{O}$ with $\mathrm{CH}_{3} \mathrm{OH}$ as internal standard. 


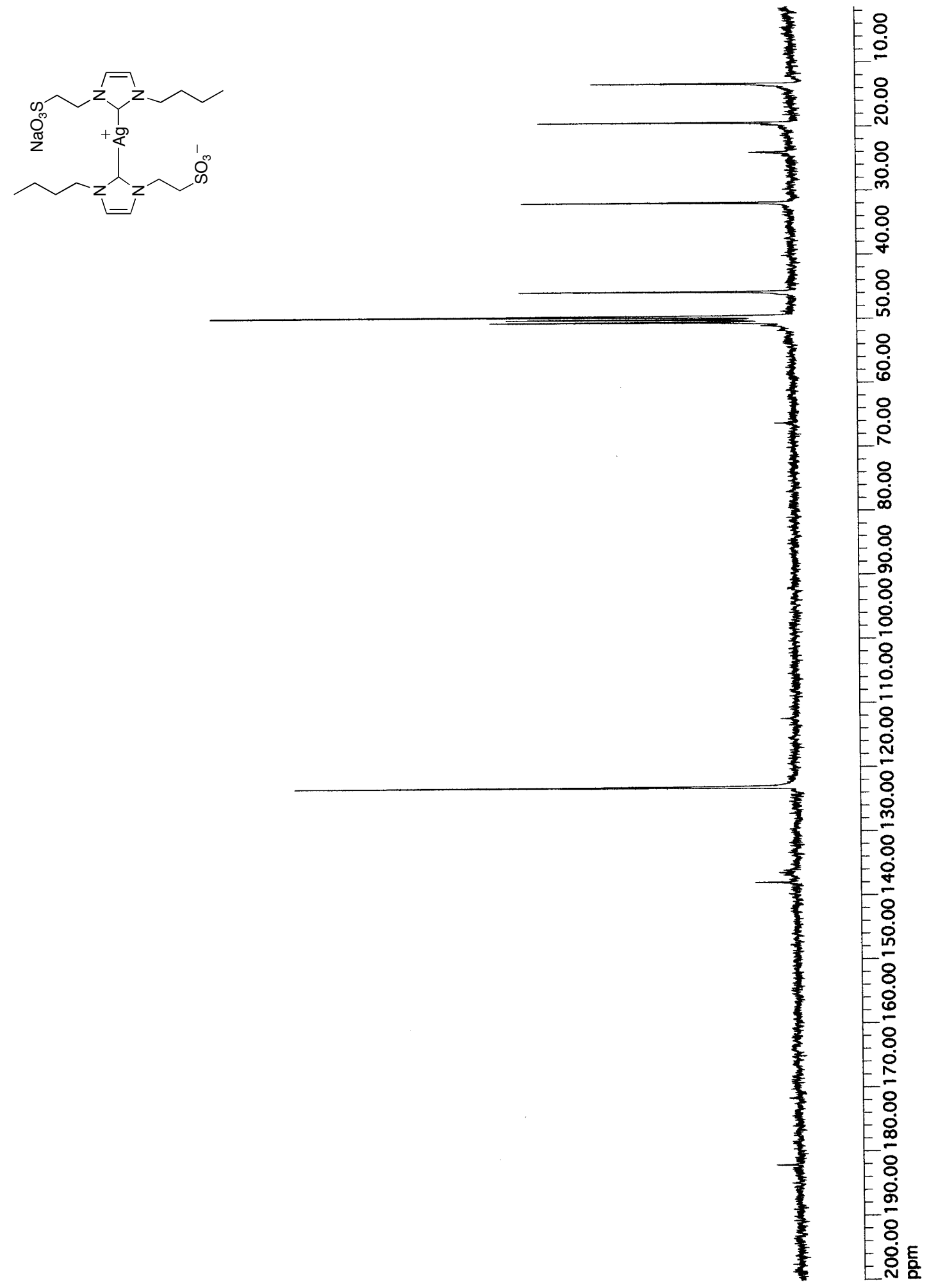

Figure $\mathrm{S} 19 .{ }^{13} \mathrm{C}$ NMR spectrum of $\mathbf{6}$ in $\mathrm{D}_{2} \mathrm{O}$ with $\mathrm{CH}_{3} \mathrm{OH}$ as internal standard. 

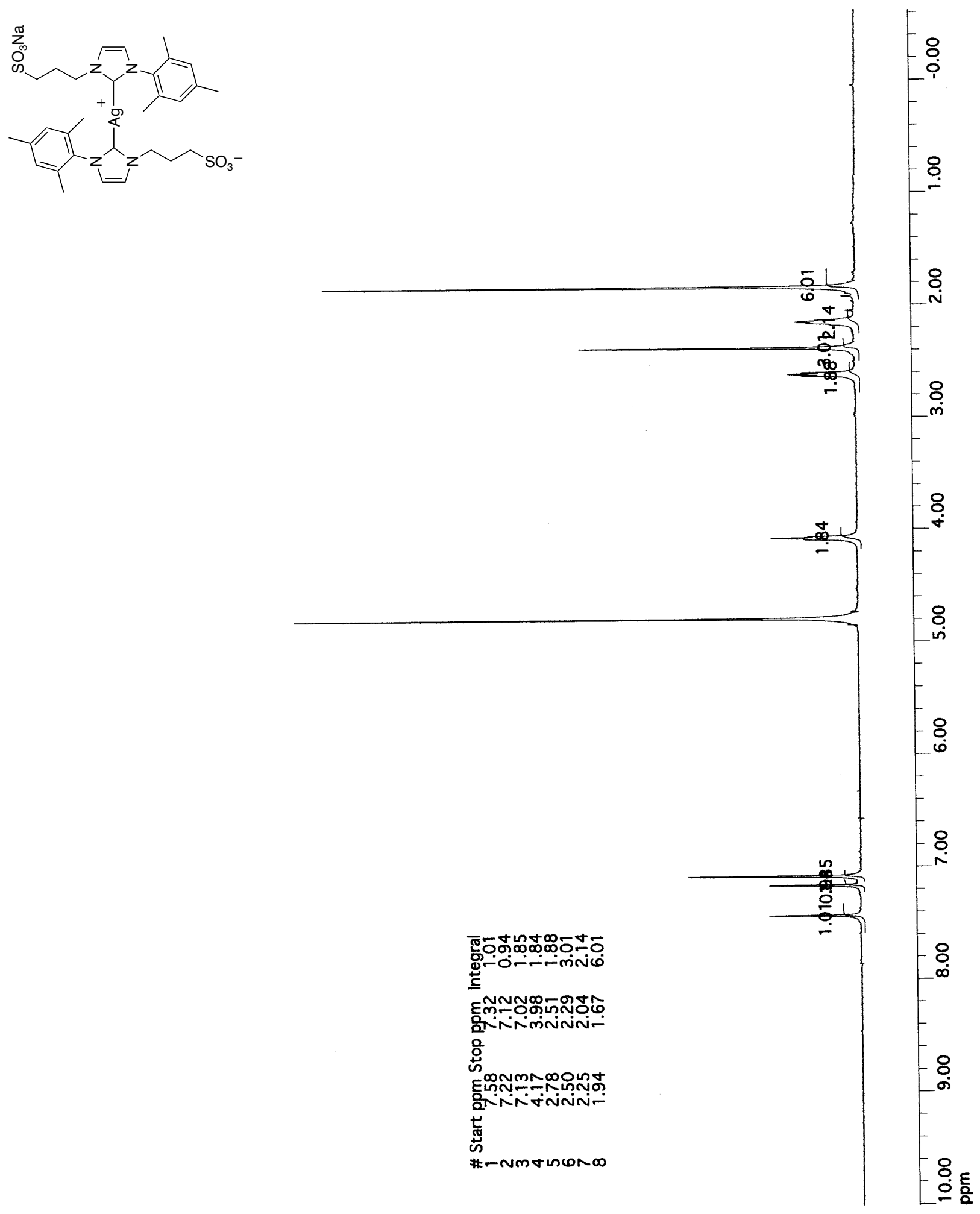

Figure S20. ${ }^{1} \mathrm{H}$ NMS spectrum of 7 in $\mathrm{D}_{2} \mathrm{O}$. 

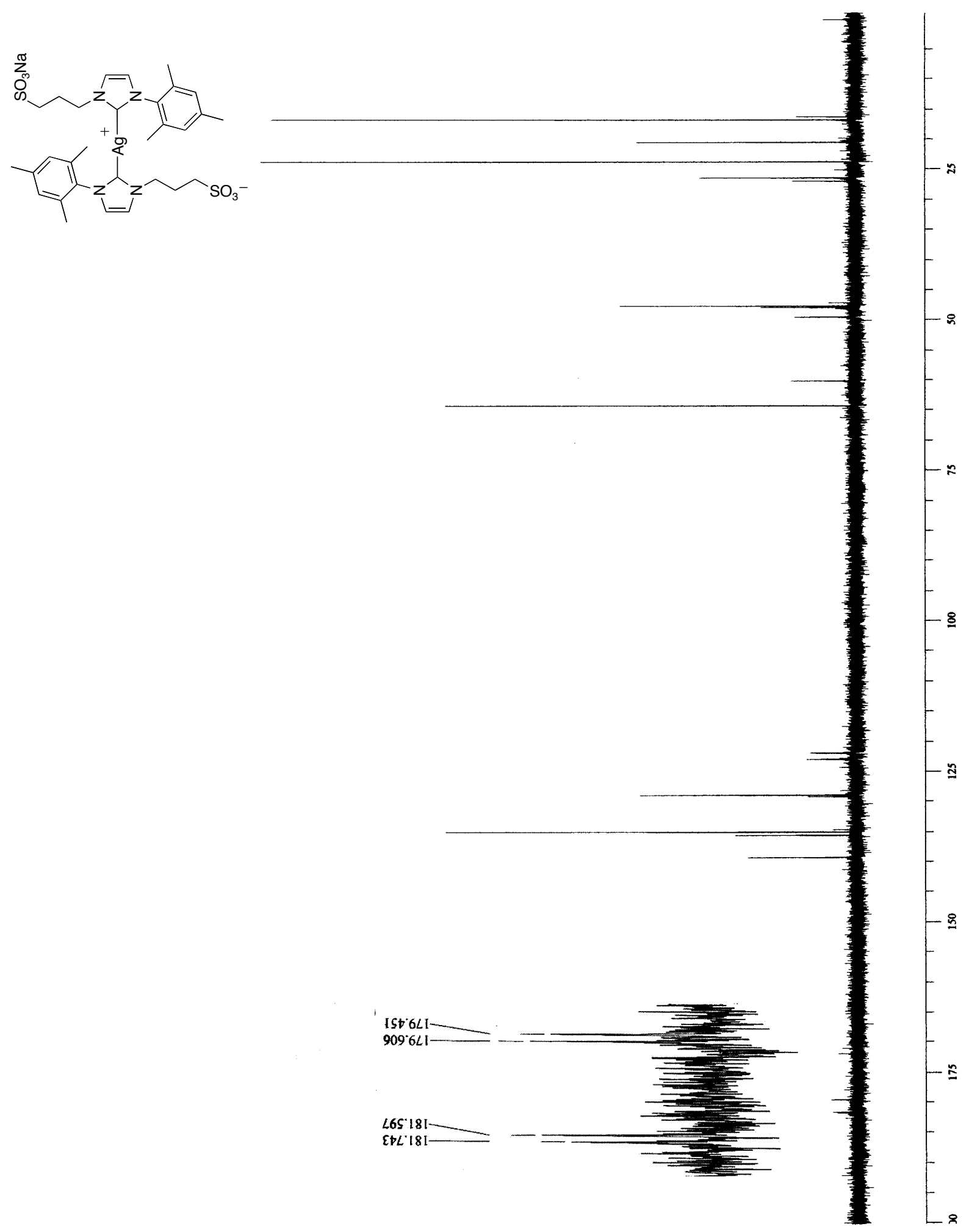

Figure $\mathrm{S} 21 .{ }^{13} \mathrm{C}$ NMR spectrum of 7 in $\mathrm{D}_{2} \mathrm{O}$ with $\mathrm{CH}_{3} \mathrm{OH}$ spike. Inset shows the split peak due to the silver-carbon coupling. 


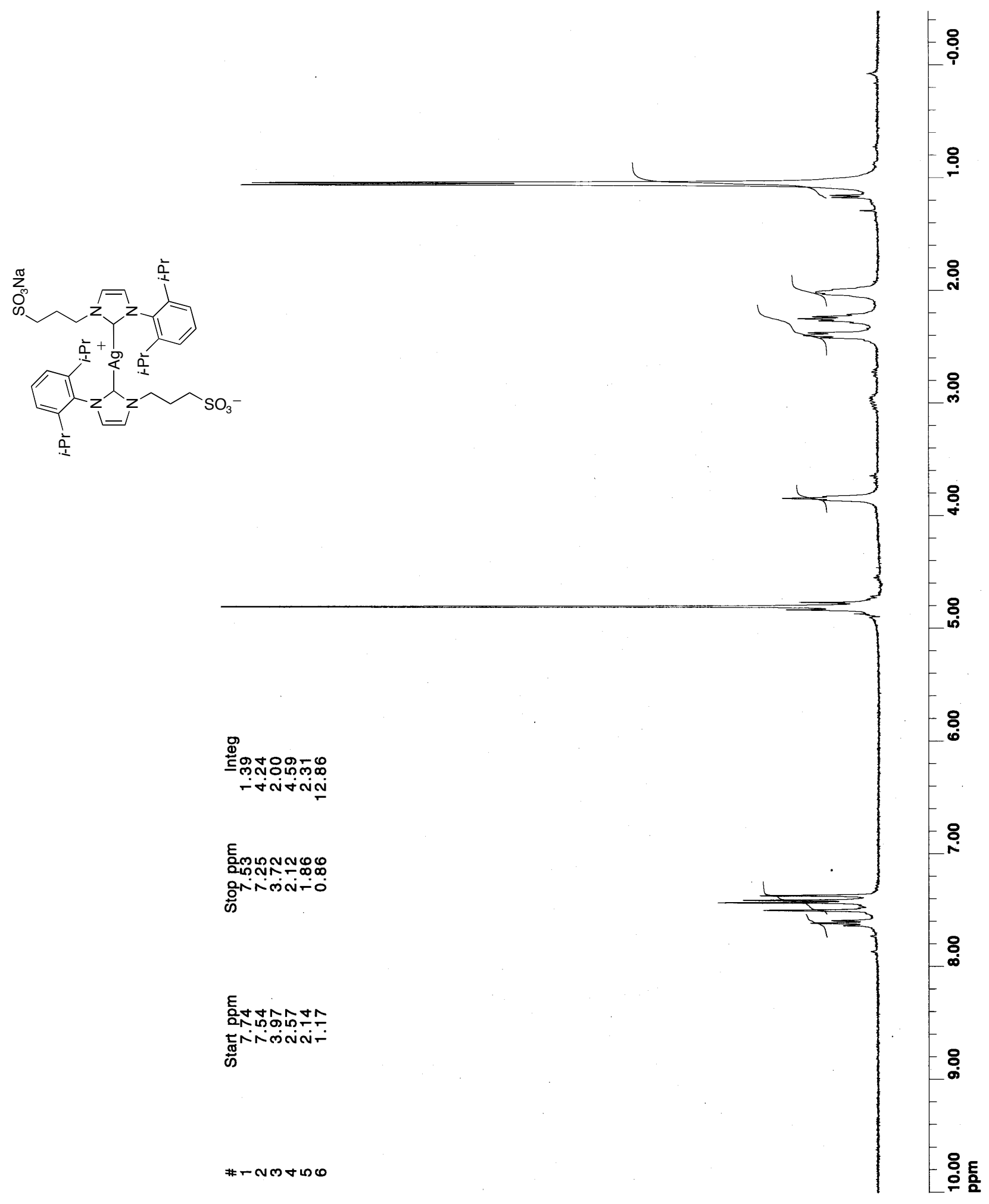

Figure S22. ${ }^{1} \mathrm{H}$ NMR spectrum of 8 in $\mathrm{D}_{2} \mathrm{O}$. 


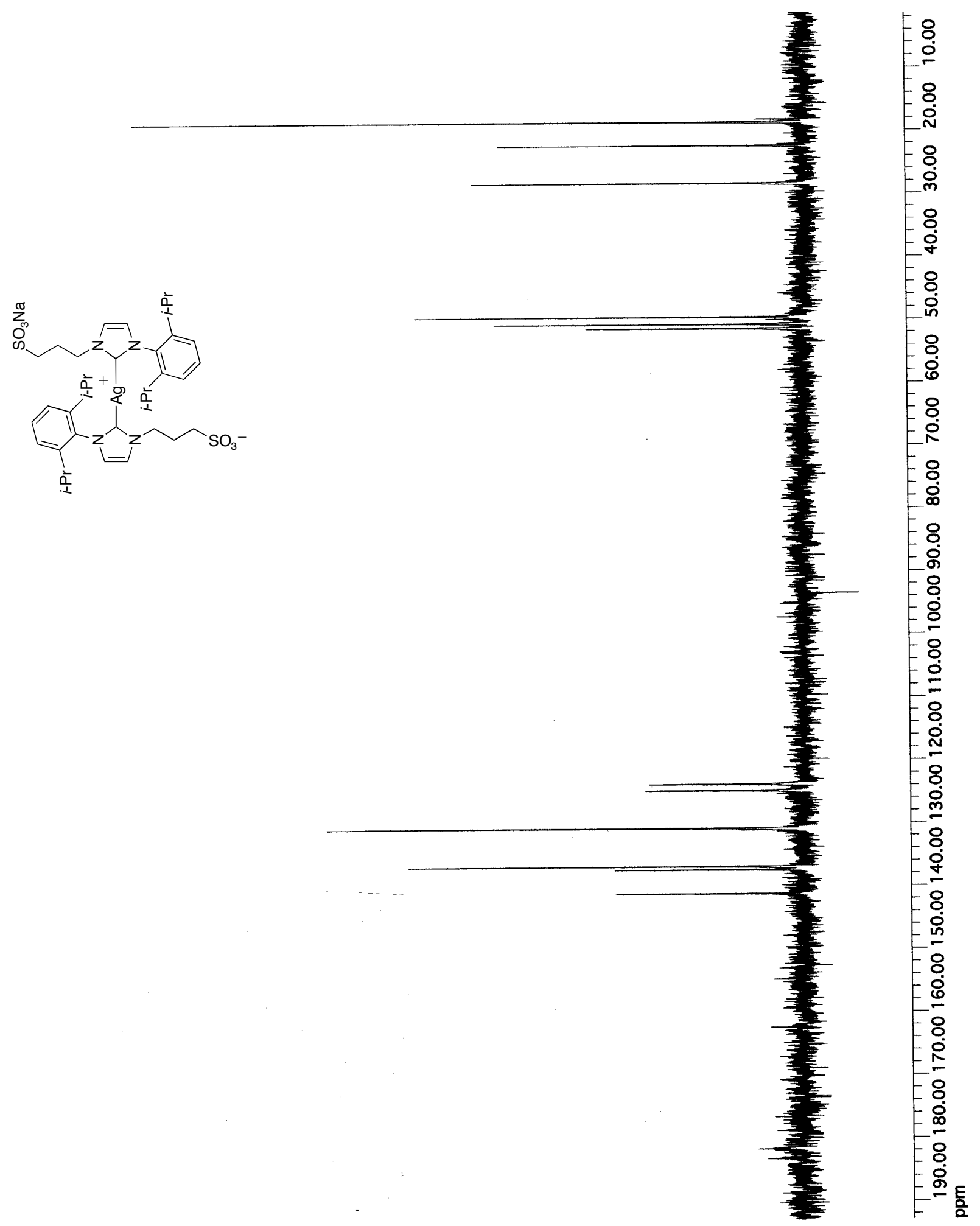

Figure S23. ${ }^{13} \mathrm{C}$ NMR spectrum of $\mathbf{8}$ in $\mathrm{D}_{2} \mathrm{O}$ with $\mathrm{CH}_{3} \mathrm{OH}$ as internal standard. 

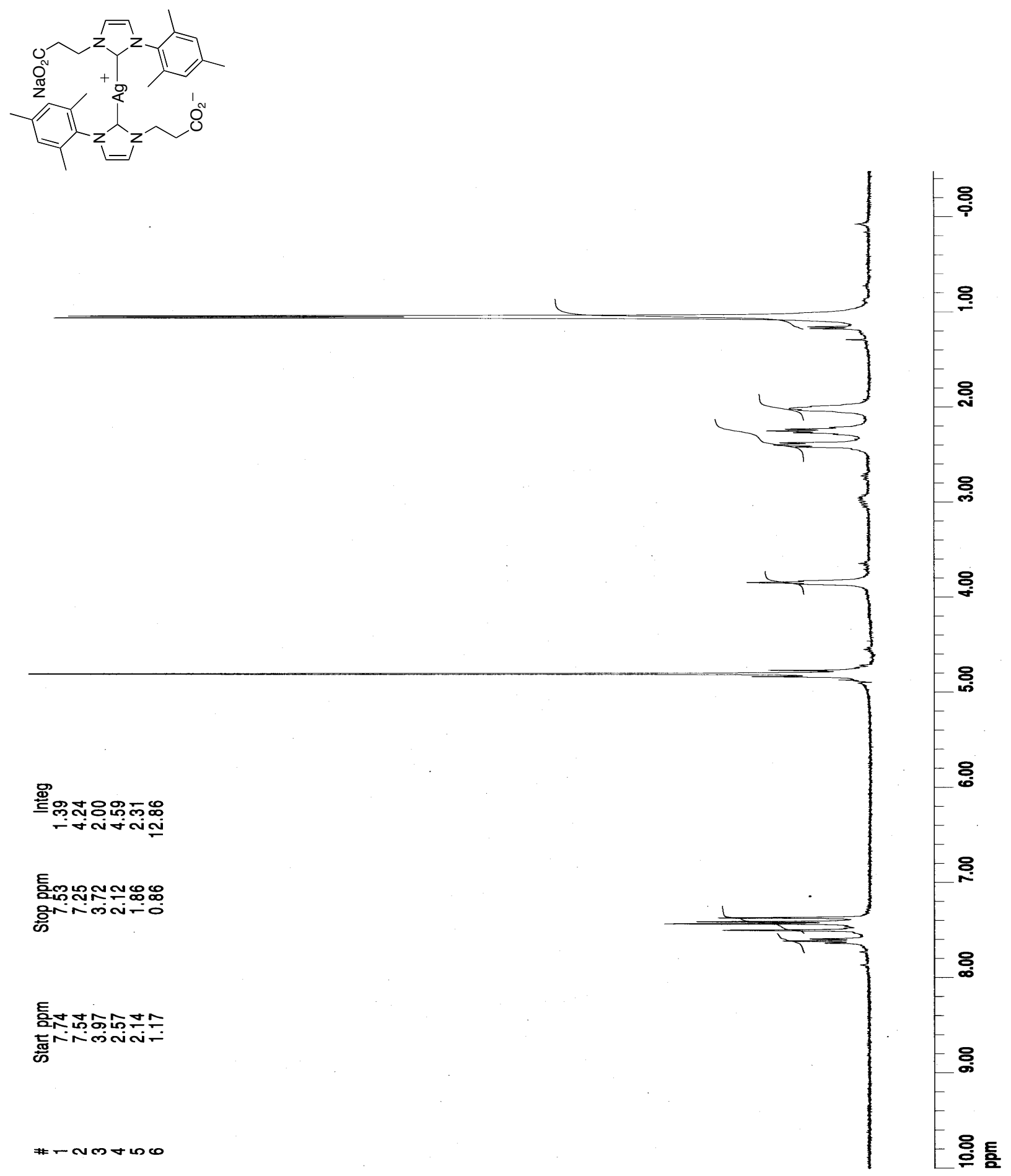

Figure S24. ${ }^{1} \mathrm{H}$ NMR spectrum of 9 in DMSO- $d_{6}$. 


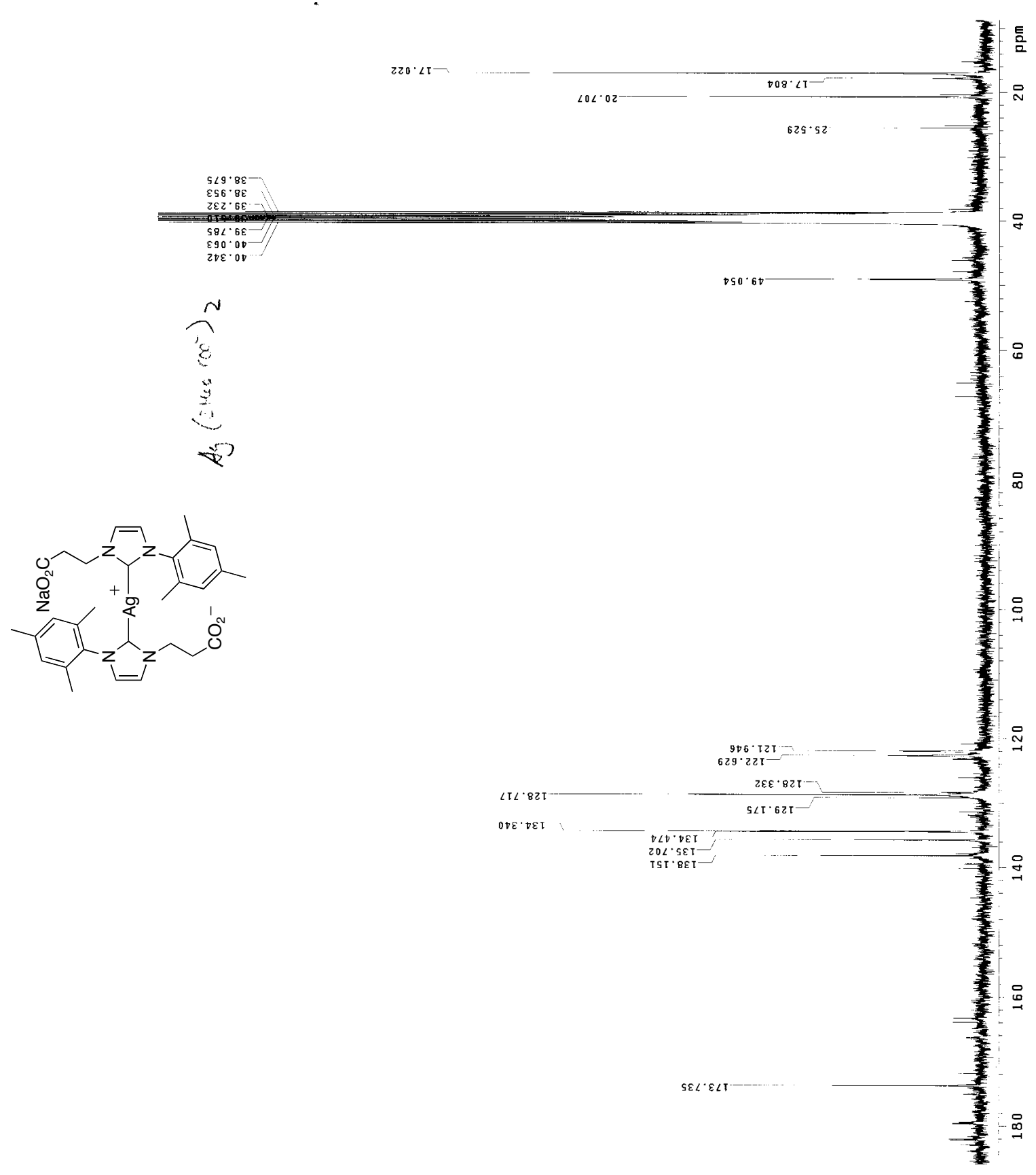

Figure S25. ${ }^{13} \mathrm{C}$ NMR spectrum of 9 in DMSO- $d_{6}$. 


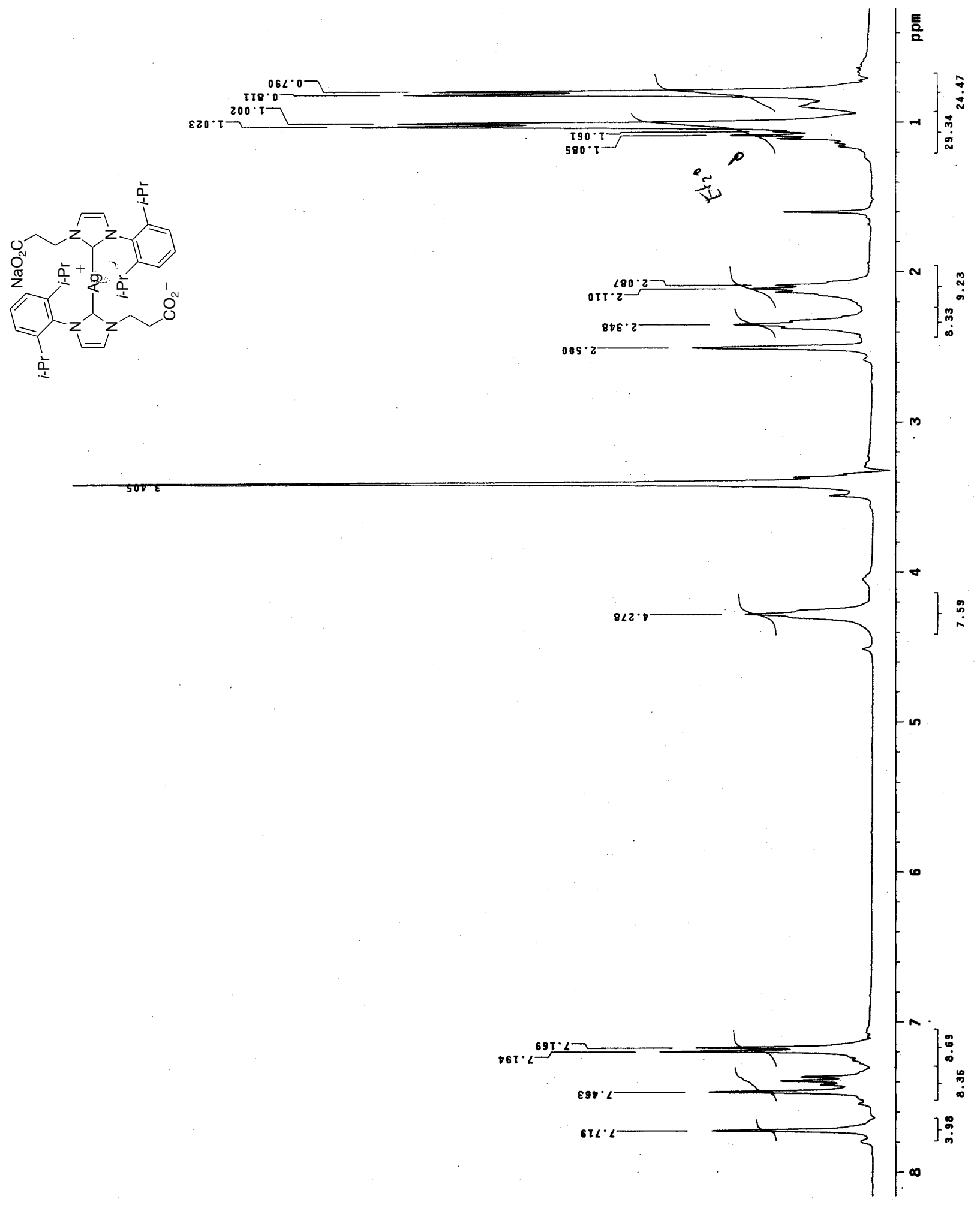

Figure S26. ${ }^{1} \mathrm{H}$ NMR spectrum of $\mathbf{1 0}$ in DMSO- $d_{6}$. 


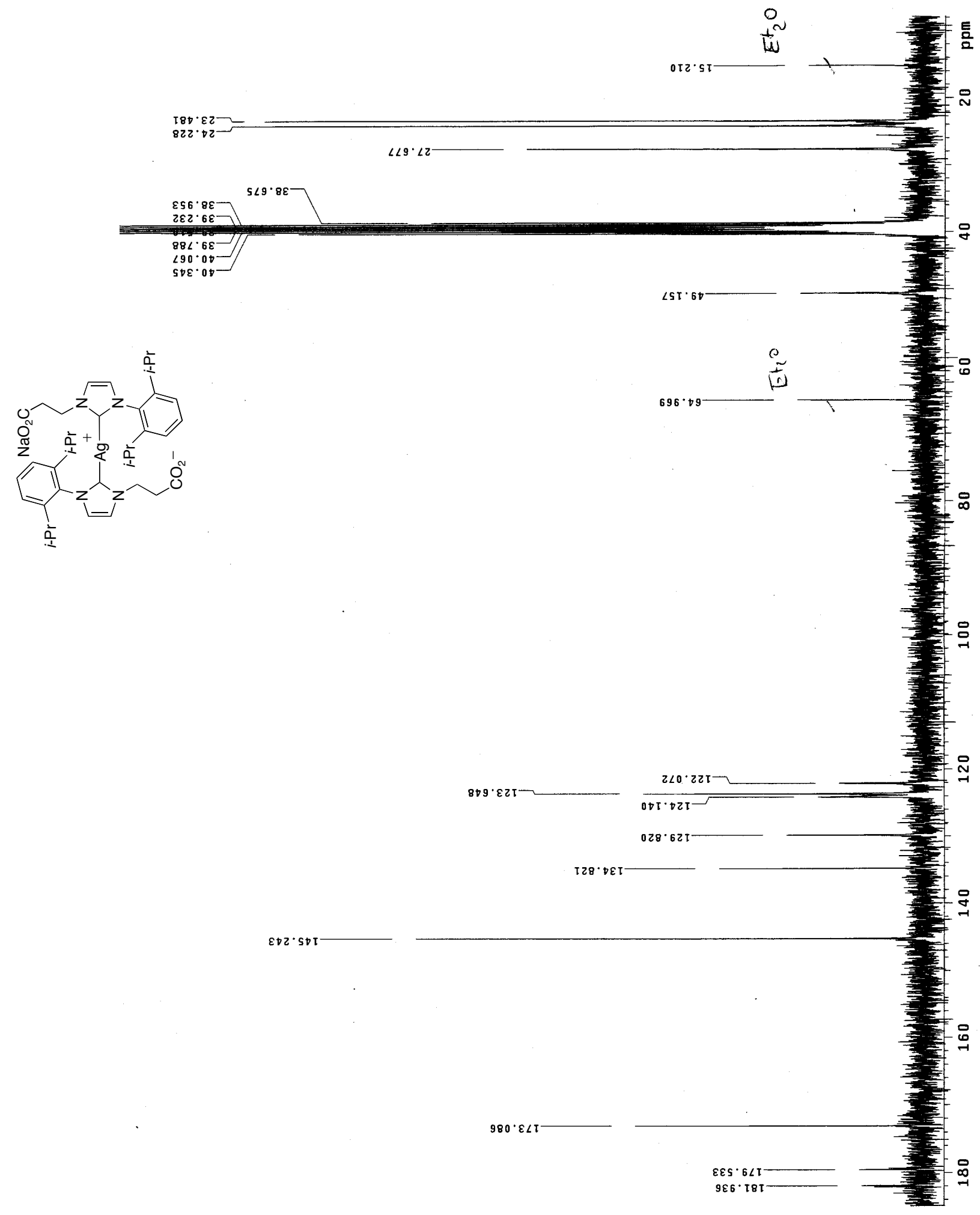

Figure S27. ${ }^{13} \mathrm{C}$ NMR spectrum of $\mathbf{1 0}$ in DMSO- $d_{6}$. 

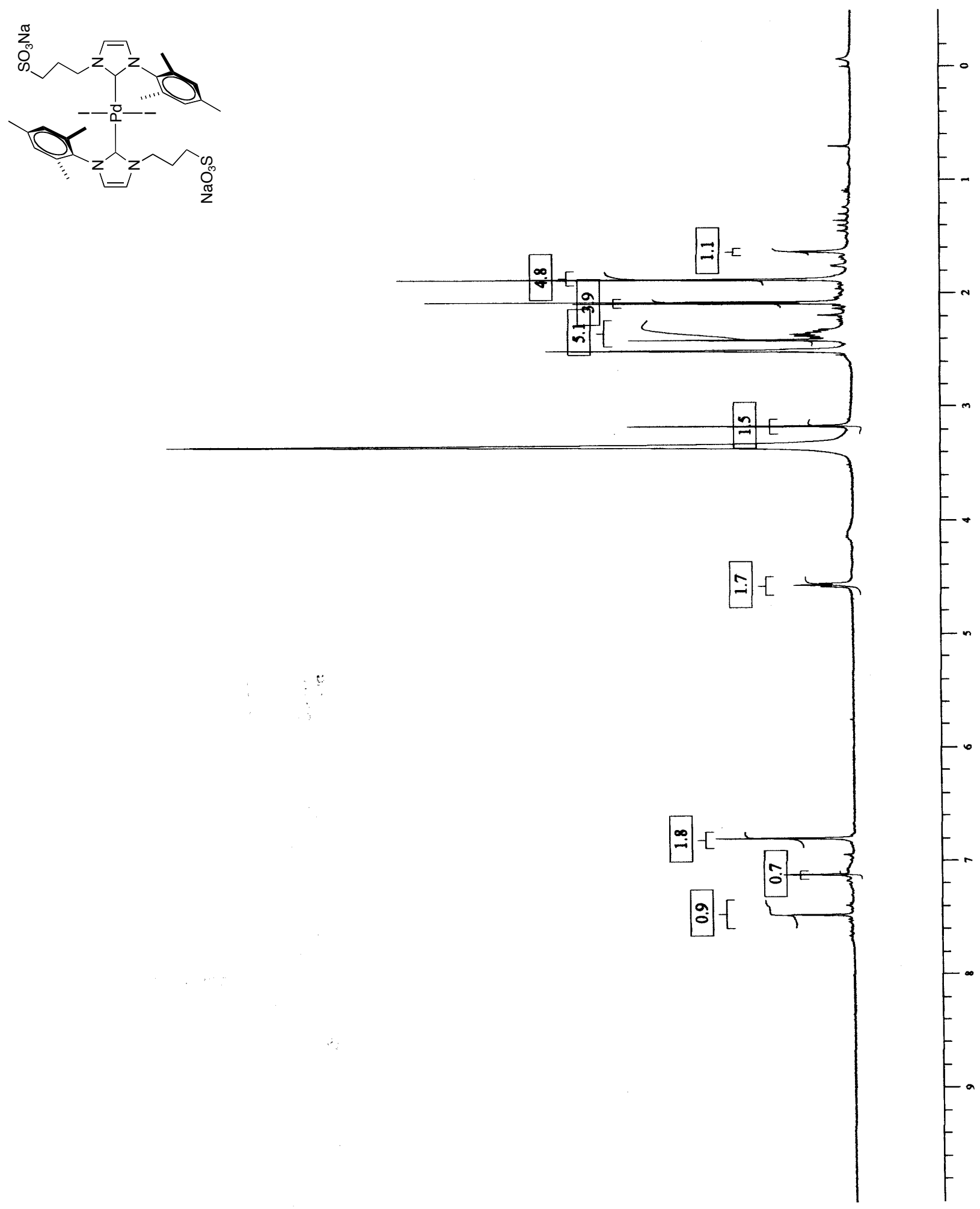

Figure S28. ${ }^{1} \mathrm{H}$ NMR spectrum of complex 11 in DMSO- $d_{6}$ 


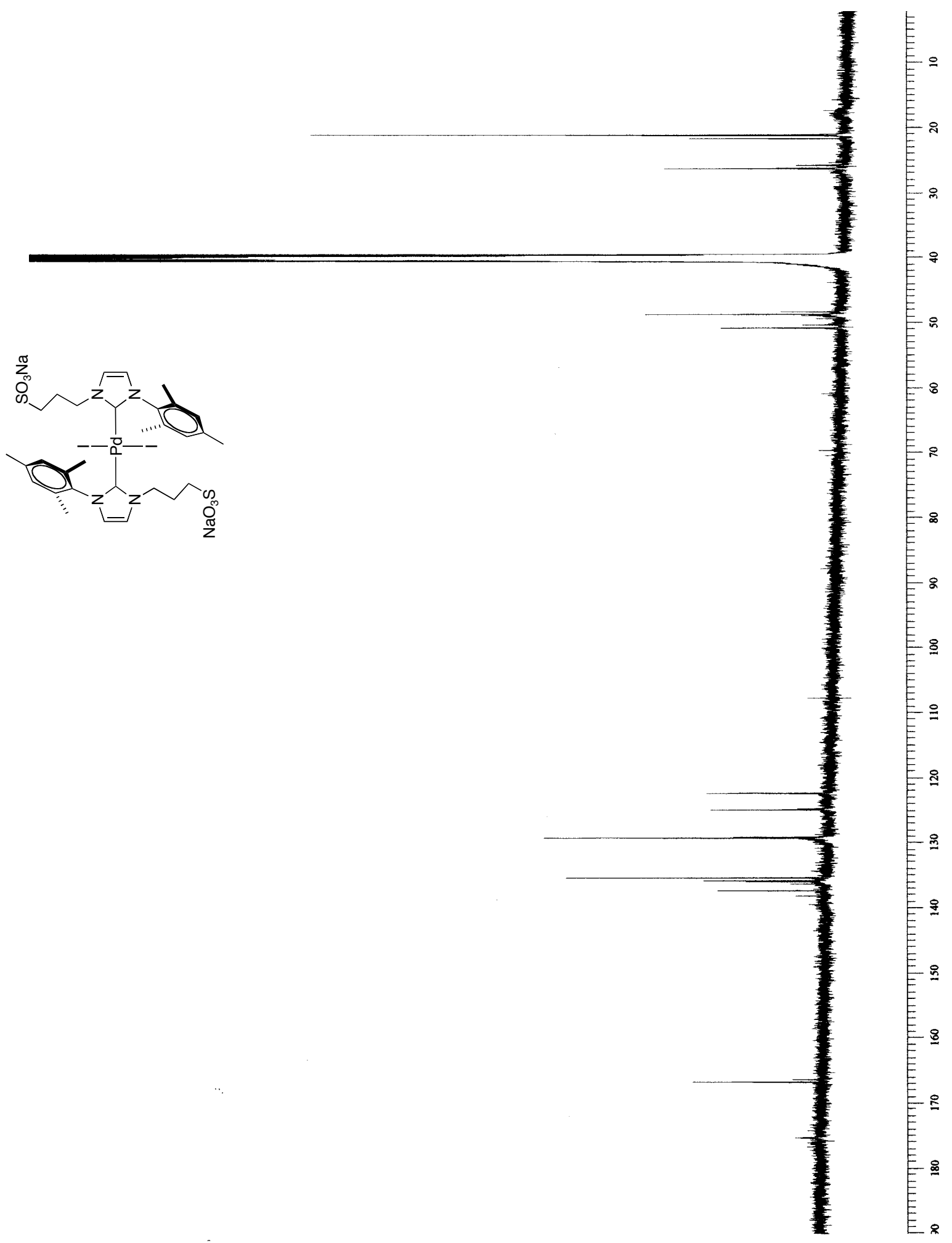

Figure S29. ${ }^{13} \mathrm{C}$ NMR spectrum of complex 11 in DMSO- $d_{6}$. 


\section{Electrospray Mass Spectra}

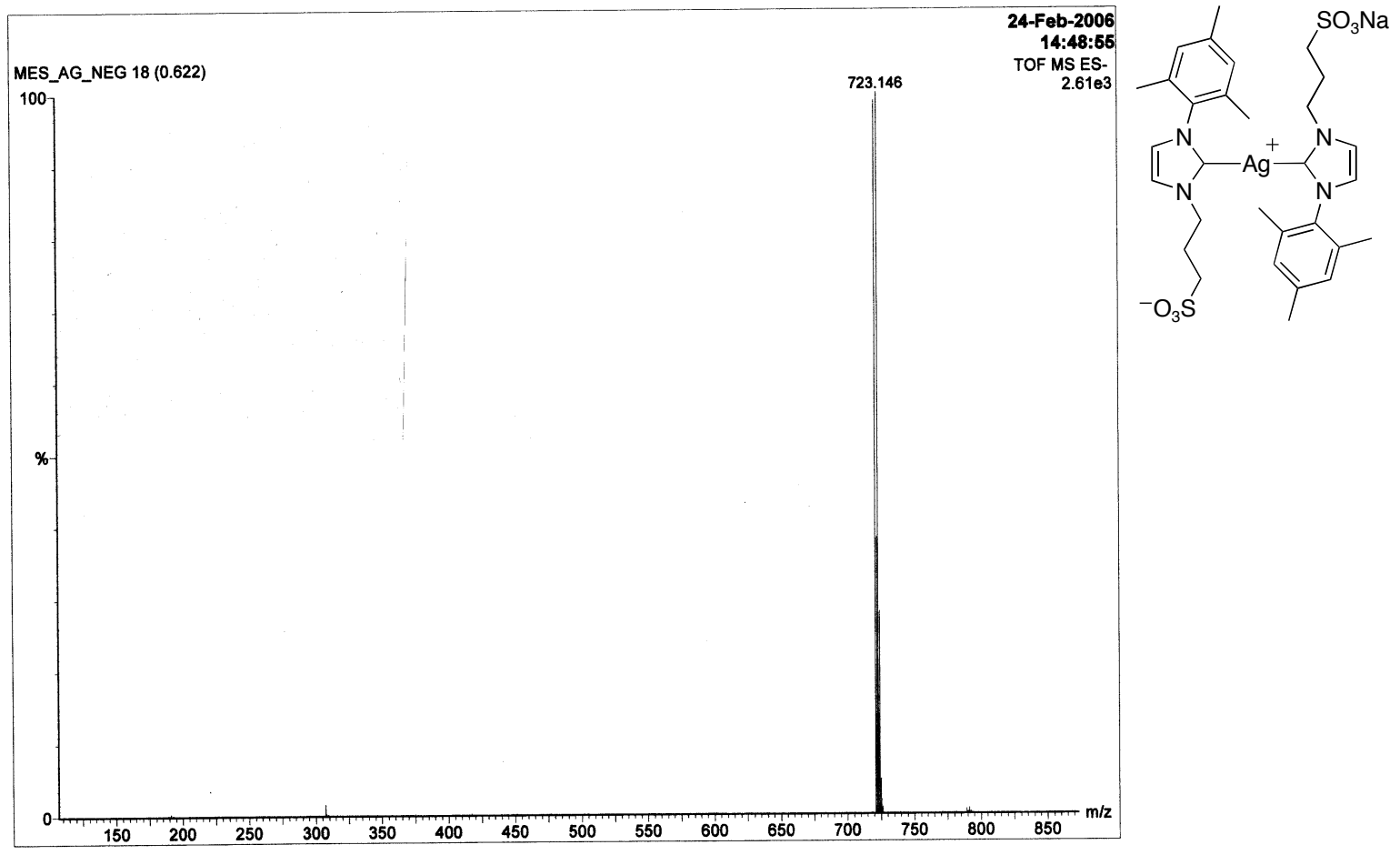

Figure S30. Negative ion mode ESI-MS of 7.

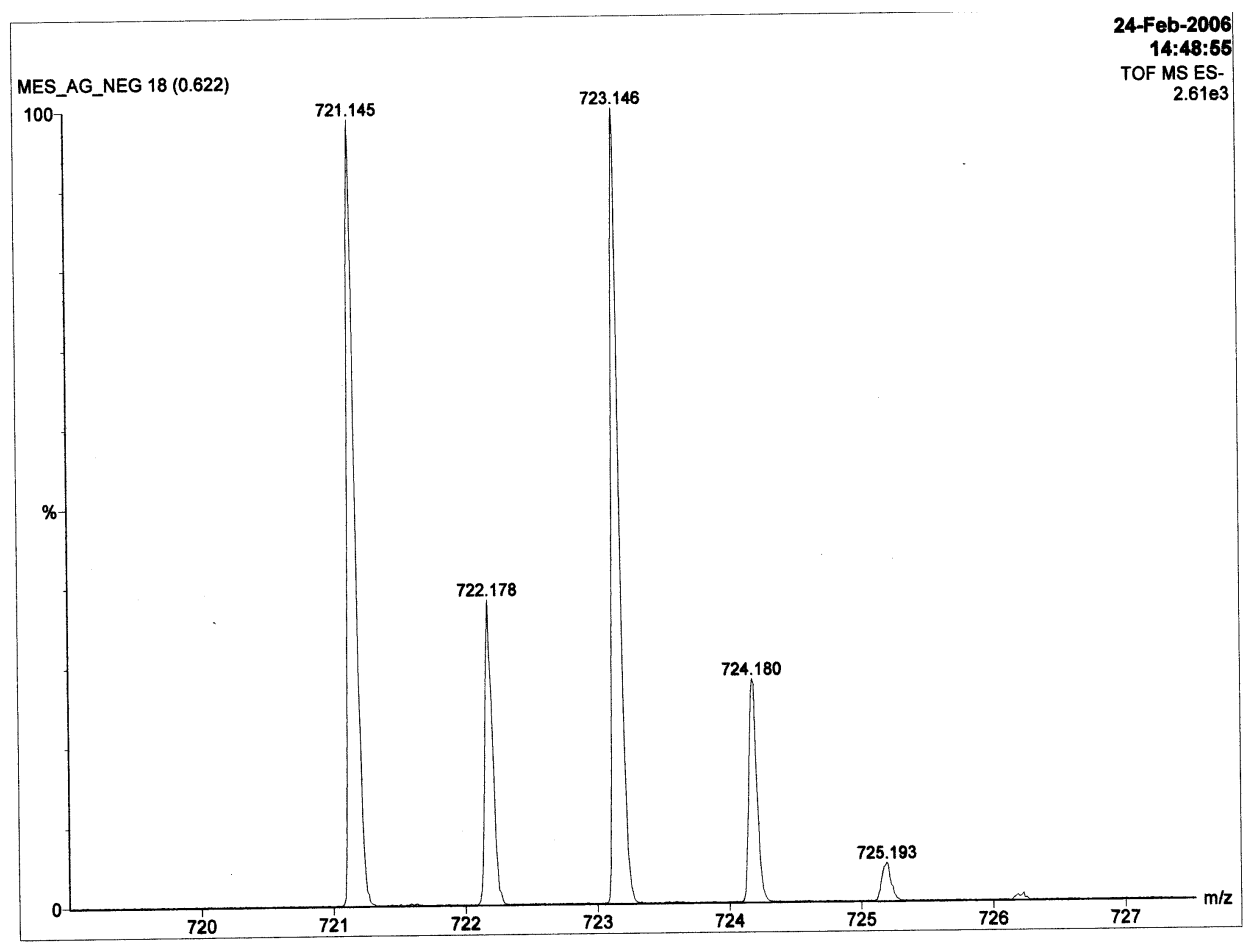

Figure S31. Negative ion mode ESI-MS of 7 expanded to show the cluster of ions at $723 \mathrm{~m} / \mathrm{z}$. 


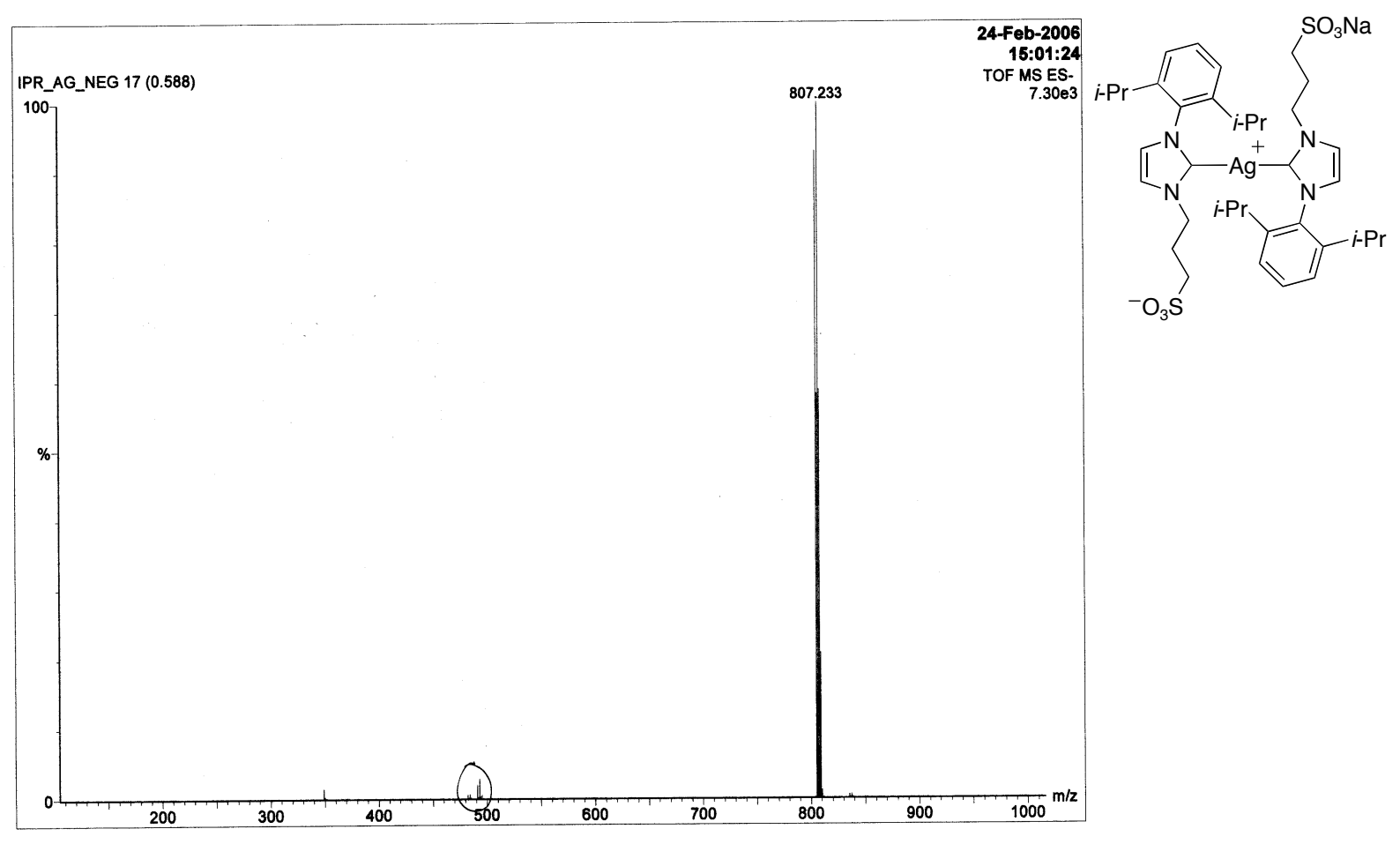

Figure S32. Negative mode ESI-MS spectrum of 8.

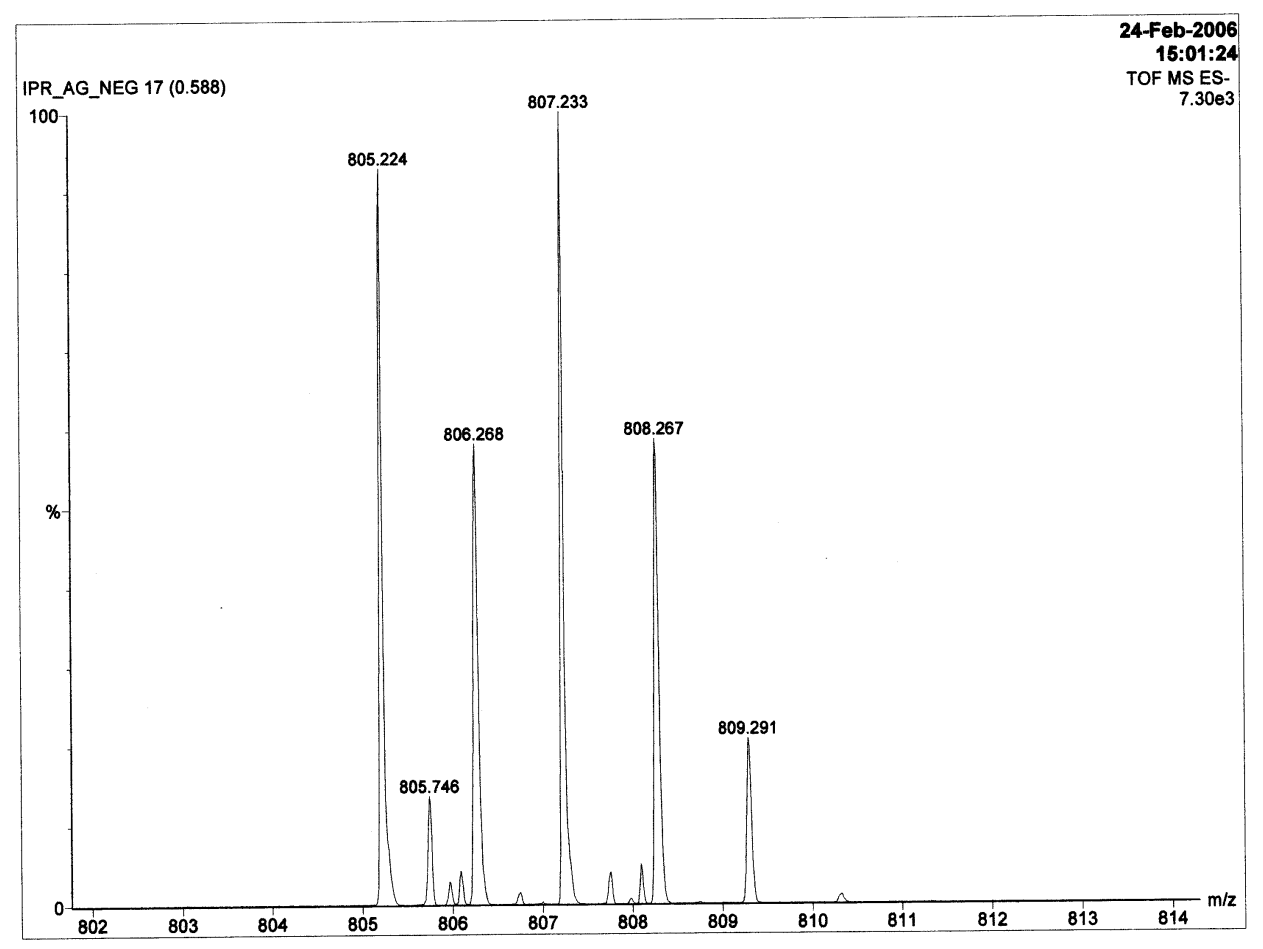

Figure S33. Negative ion mode ESI-MS spectrum of 8 expanded to show cluster of ions at 807 $\mathrm{m} / \mathrm{z}$. 


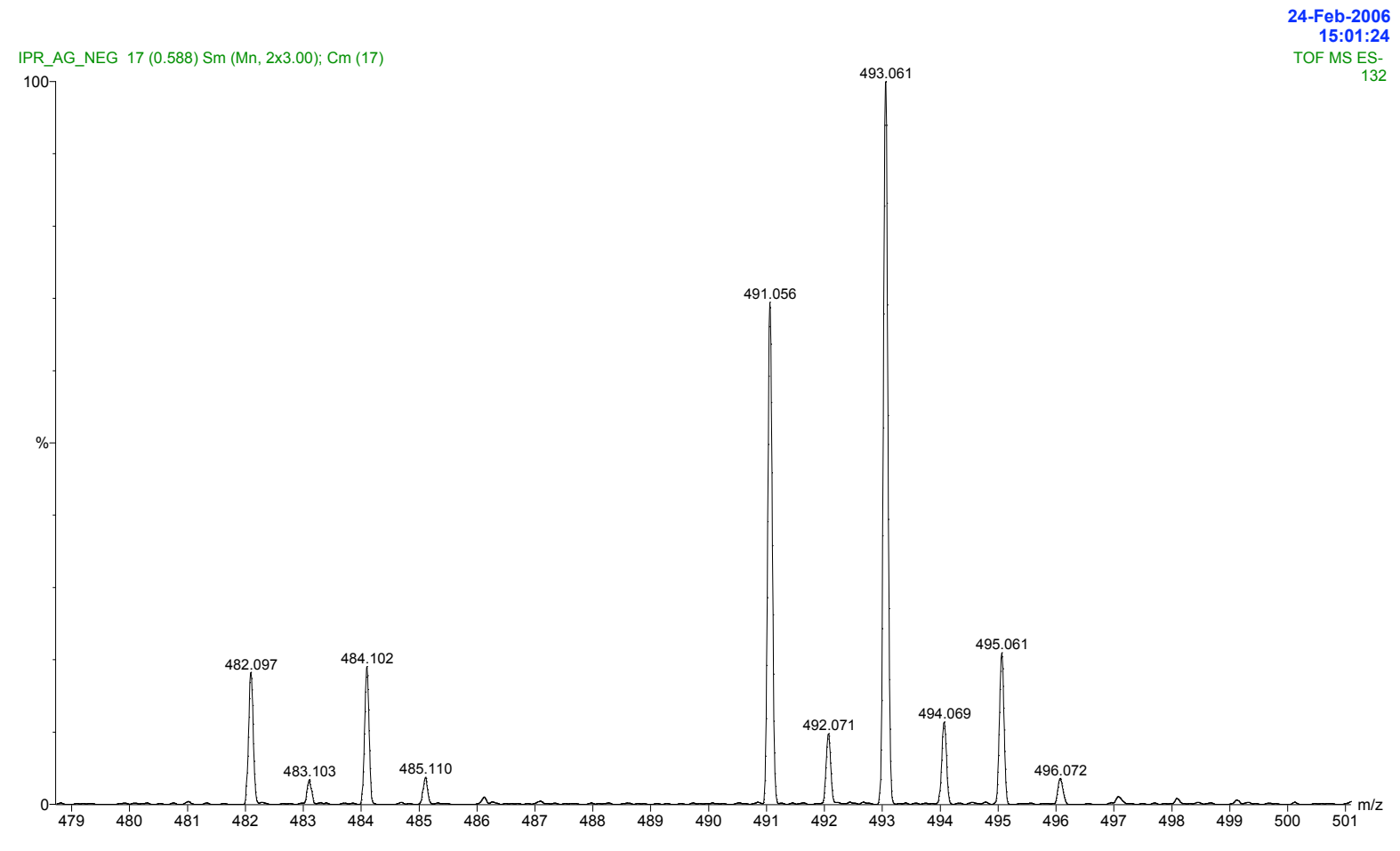

Figure S34. Negative ion mode ESI-MS spectrum of $\mathbf{8}$ expanded to show clusters of ions at 482 and $491 \mathrm{~m} / \mathrm{z}$.

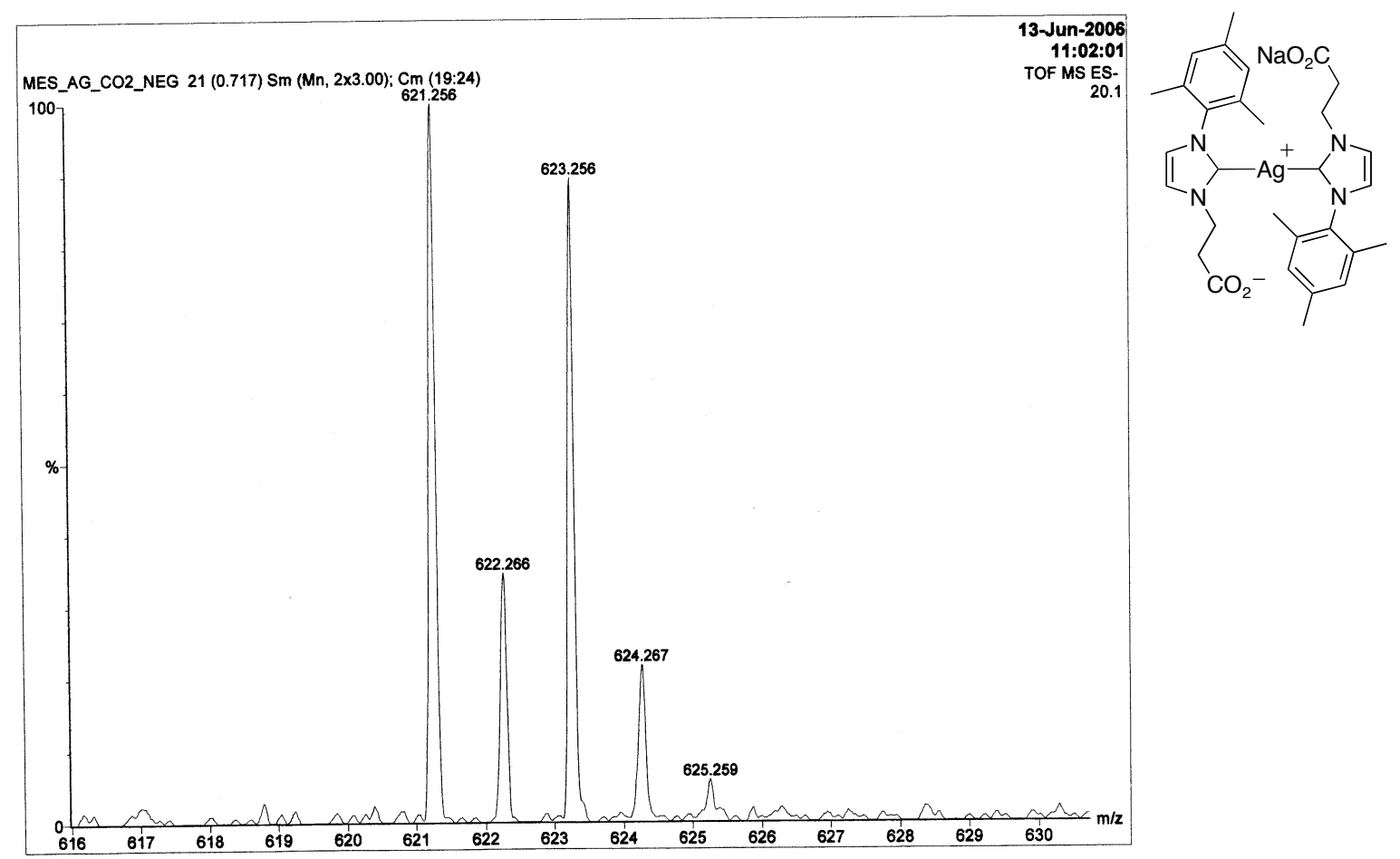

Figure S35. Negative ion mode ESI-MS spectrum of 9 expanded to show clusters of ions at 621 $\mathrm{m} / \mathrm{z}$. 


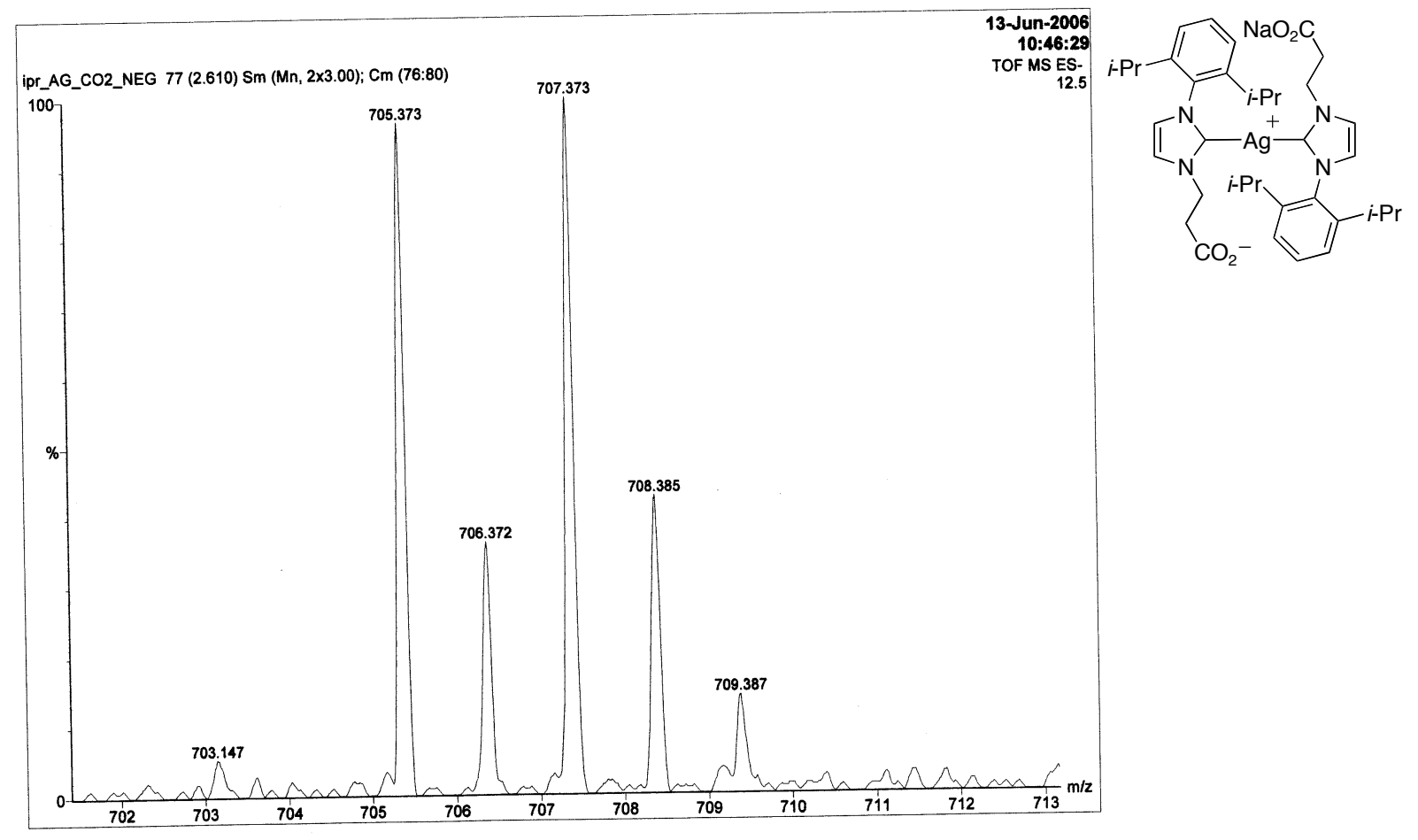

Figure S36. Negative ion mode ESI-MS spectrum of $\mathbf{1 0}$ expanded to show clusters of ions at $705 \mathrm{~m} / \mathrm{z}$.

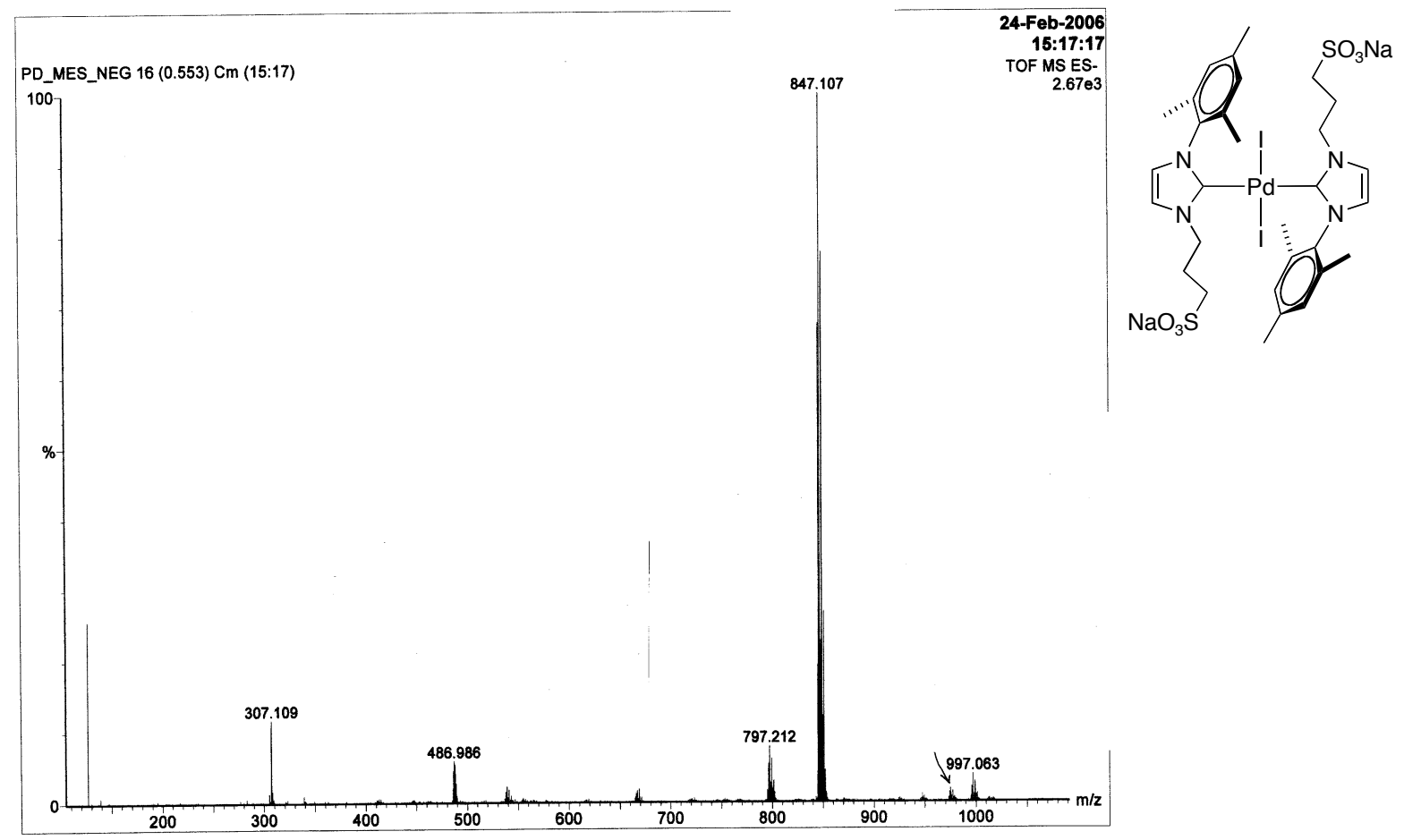

Figure S37. Negative mode ESI-MS spectrum of complex 11. 


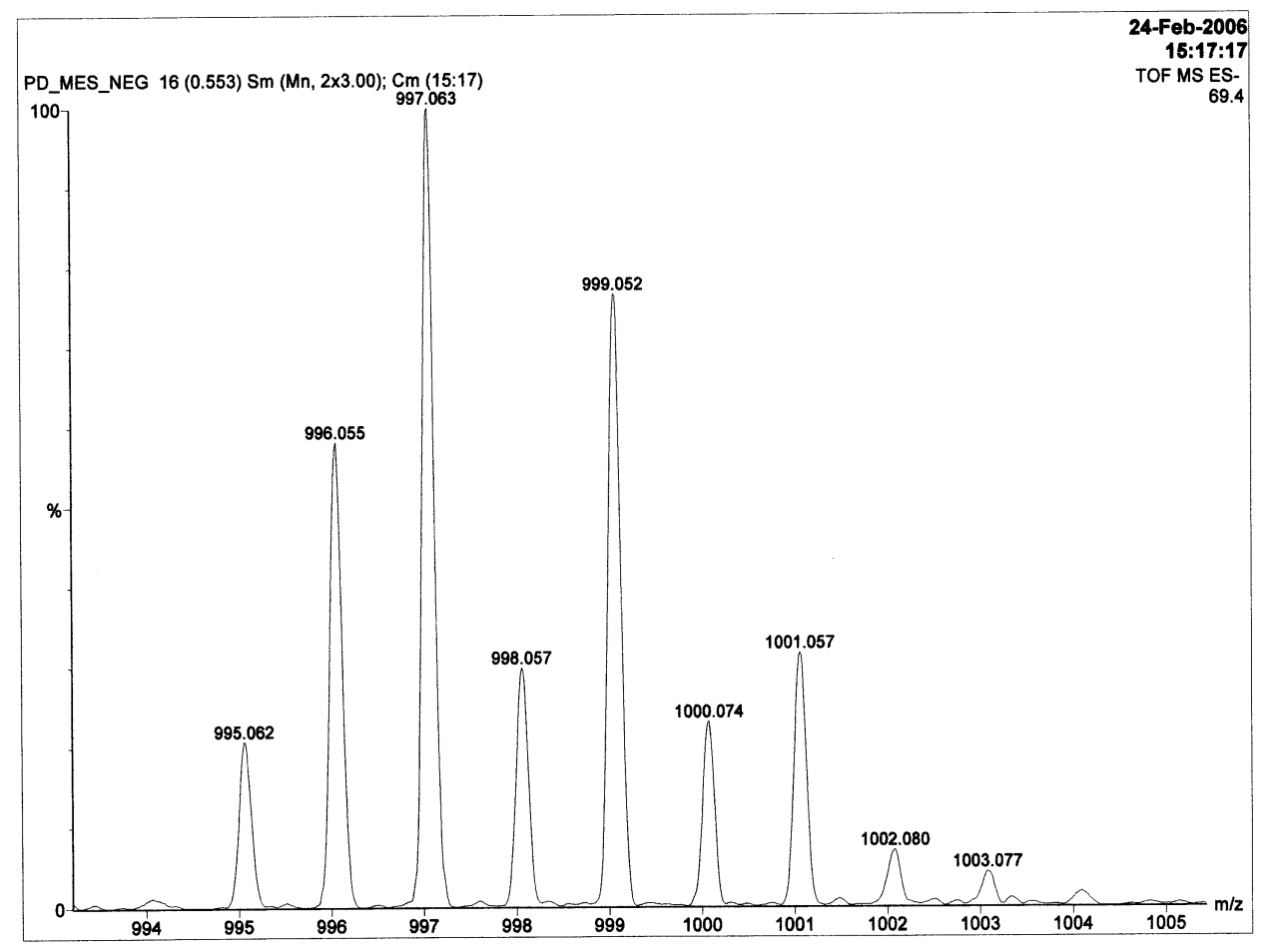

Figure S38. Negative mode ESI-MS spectrum of complex 11 expanded to show cluster of peaks at $997 \mathrm{~m} / \mathrm{z}$.

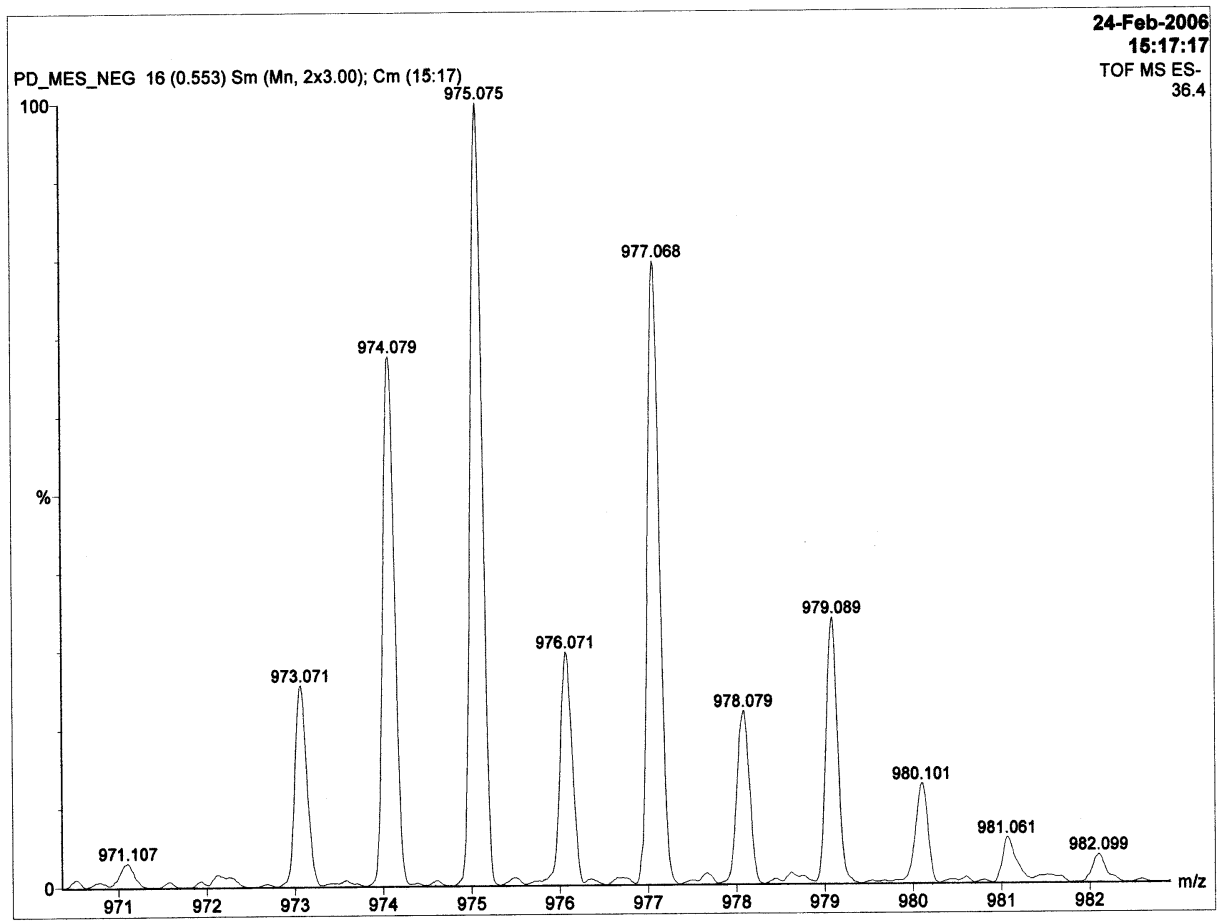

Figure S39. Negative mode ESI-MS spectrum of complex 11 expanded to show cluster of peaks at $975 \mathrm{~m} / \mathrm{z}$. 


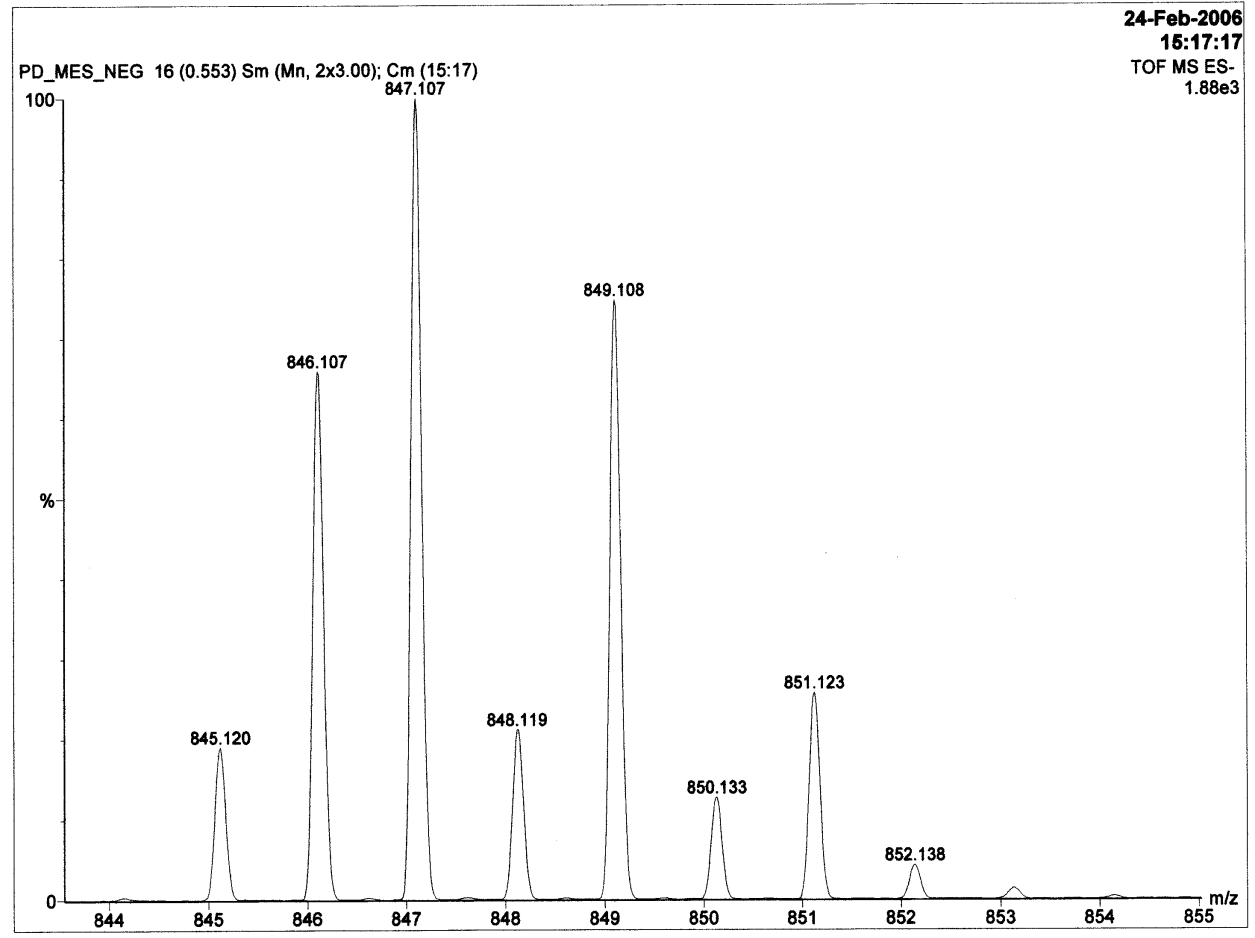

Figure S40. Negative mode ESI-MS spectrum of complex 11 expanded to show cluster of peaks at $847 \mathrm{~m} / \mathrm{z}$.

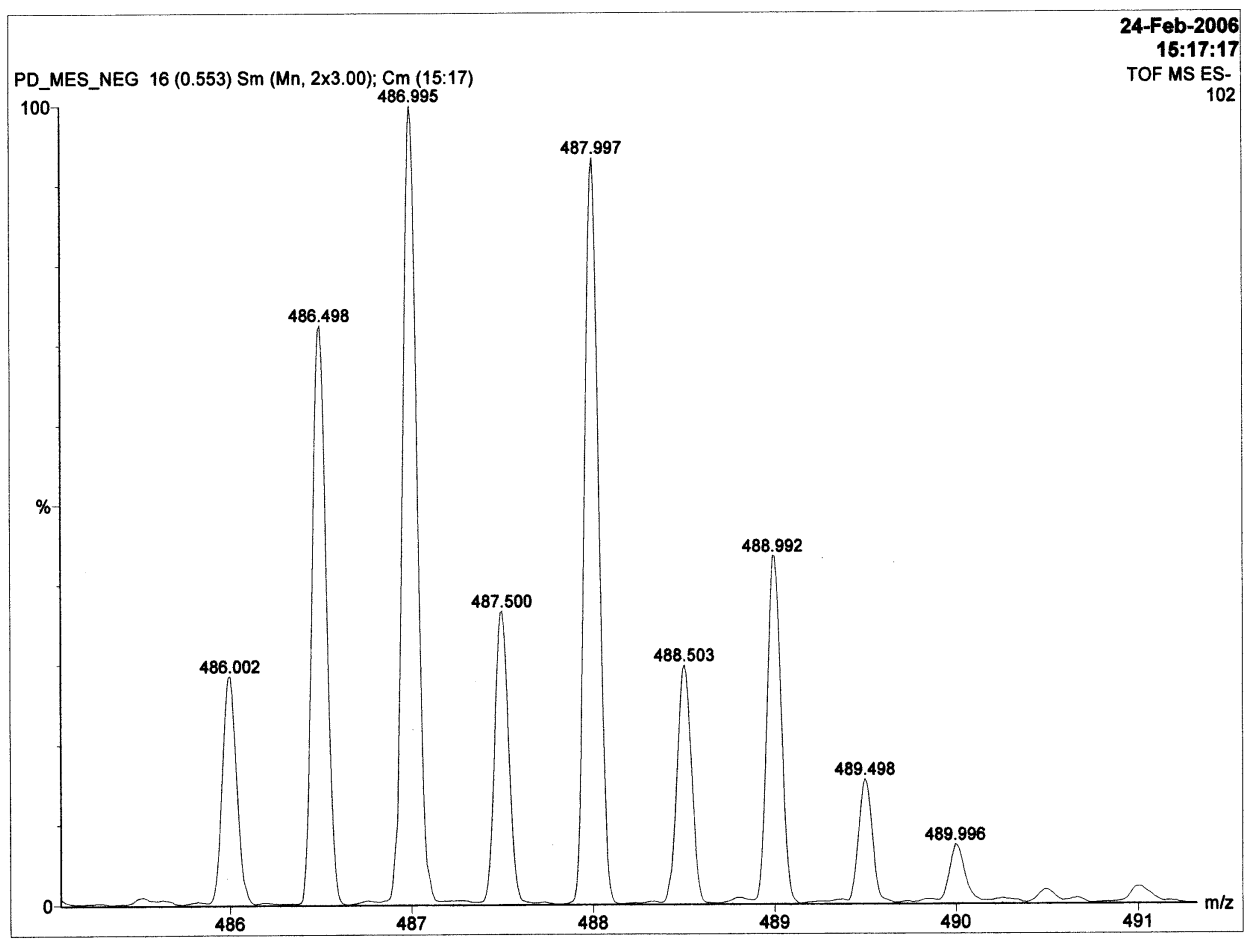

Figure S41. Negative mode ESI-MS spectrum of complex 11 expanded to show cluster of dianionic peaks at $487 \mathrm{~m} / \mathrm{z}$. 